\title{
Discharge Cathode Electron Energy Distribution Functions in a 40-cm NEXT-type Ion Engine
}

\author{
Daniel A. Herman ${ }^{\dagger}$ and Alec D. Gallimore." \\ Plasmadynamics and Electric Propulsion Laboratory \\ University of Michigan, Ann Arbor, MI 48109 USA
}

\begin{abstract}
Electron energy distribution functions (EEDF's) are presented over a two-dimensional array of locations in the discharge chamber of a $40-\mathrm{cm}$ diameter ring-cusp ion thruster. The EEDF's are obtained using two different techniques illustrating comparable results. A distinct difference in the EEDF's measured through the double layer potential gradient, which transitions between the low-potential discharge cathode plume and the appropriated discharge voltage bulk discharge plasma, is observed for thruster operation with and without beam extraction. This result indicates the coupled nature of the beam and discharge plasmas and highlights the need for beam extraction to reproduce flight-like conditions. For operation with beam extraction, the single-hump near discharge cathode assembly (DCA) distributions transition to double-hump or plateau-like distributions in the double layer and eventually become single-hump distributions with a high-energy tail in the bulk discharge. Radial acceleration across the double layer is responsible for the formation of the second hump in the distribution explaining the rise in electron temperature outside the discharge cathode plume that is observed. Axial acceleration near the DCA is also discernable, but to a lesser extent. These observations agree with measured $40-\mathrm{cm}$ plasma potentials inside the discharge chamber. The discharge-only EEDF's demonstrate a second hump that is greatly reduced and in many cases not observed. Shorting of the discharge keeper to discharge cathode common did not have an effect on the near DCA plasma structure outside of the keeper sheath.
\end{abstract}

\section{Nomenclature}

$A(E)$

$A_{p}$

$=$ ac signal amplitude, $\mathrm{V}$

$=$ lock-in amplifier output signal

$=$ electrode surface area, $\mathrm{m}^{2}$

$=$ magnetic field magnitude, Gauss

$=$ effective exhaust velocity, $\mathrm{km} / \mathrm{s}$

$=$ electron energy with respect to local plasma potential, $\mathrm{V}$

$=$ electron charge, $\mathrm{C}$

$=$ electron energy distribution function, $\mathrm{m}^{-3} \mathrm{eV}^{-1}$

$=$ gravity constant at sea level on earth, $\mathrm{m} / \mathrm{s}^{2}$

$=$ electron current to electrode, $\mathrm{mA}$

$=$ first derivative of electron current

$=$ second derivative of electron current

$=$ third derivative of electron current

$=$ fourth derivative of electron current

$=$ probe current, $\mathrm{mA}$

$=$ specific impulse, $\mathrm{s}$

$=$ acceleration grid current, $\mathrm{mA}$

$=$ beam current, $\mathrm{A}$

$J_{d c} \quad=$ discharge current, A

${ }^{*}$ Color copies available at http://www.engin.umich.edu/dept/aero/spacelab/publications/conf_pub.html.

${ }^{\dagger}$ Graduate Student, Aerospace Engineering, hermo@engin.umich.edu, 1919 Green Rd Room B107, Member AIAA.

* Professor and Laboratory Director, Aerospace Engineering, Alec.gallimore@umich.edu, Associate Fellow AIAA. 


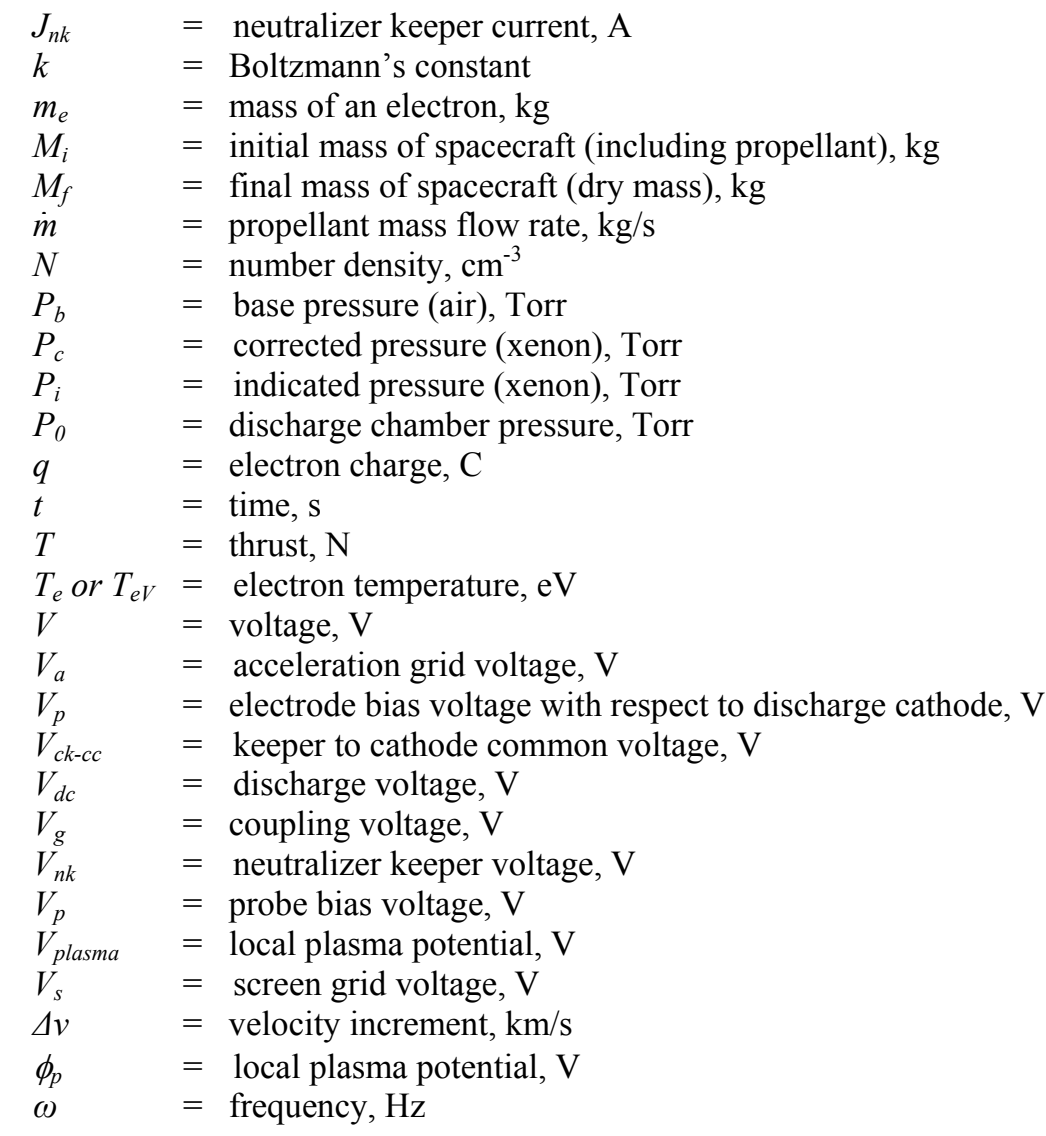

\section{Introduction}

$\mathrm{T}$

HE motivation for high exhaust velocity propulsion technology investment is illustrated by the Rocket Equation or Tsiolkovsky's Equation. Named after famous mathematics teacher Konstantin Tsiolkovsky, who in 1903 first published its derivation, the Rocket Equation identifies exhaust velocity as the important performance parameter in rocket propulsion. ${ }^{1}$ The Rocket Equation illustrates that the fraction of the original vehicle mass that can be accelerated through a given velocity increment, $\Delta \mathrm{v}$, is a negative exponential in the ratio of that velocity increment to the effective exhaust velocity, c.

$$
\frac{M_{f}}{M_{i}}=e^{-\frac{\Delta v}{c}}=e^{-\frac{\Delta v}{I_{s p} g_{0}}}
$$

As illustrated in Eq. 1, the effective exhaust velocity is related to the performance parameter specific impulse, Isp, which is defined as the total impulse per unit weight of propellant, given by Eq. 2 .

$$
I_{s p} \equiv \frac{T}{\dot{m} g_{0}}=\frac{c}{g_{0}}
$$

Tsiolkovsky's Equation, Eq. 1, establishes the need for an effective exhaust velocity that is comparable with the mission $\Delta \mathrm{v}$ if a significant fraction of the original mass is to be brought to the final velocity. Deep space missions are prime examples of high- $\Delta \mathrm{v}$ missions that benefit from high exhaust velocity, but this can also be true for northsouth station-keeping (NSSK) requirements in which long satellite lifetimes may require substantial $\Delta \mathrm{v}$ 's to overcome the solar radiation pressure drag and gravity gradients to maintain their orbit. It is clear that there are many missions that can benefit from high exhaust velocity, or equivalently high specific impulse, technologies. 
Ion thrusters are high-efficiency, high specific impulse $\left(\mathrm{I}_{\mathrm{sp}}\right)$ propulsion systems that are being proposed as the primary propulsion source for a variety of missions. Ion thruster technology has enabled new missions that had not been feasible using liquid propellant rocket technology. The NASA Solar Electric Propulsion Technology Applications Readiness (NSTAR) 30-cm ion thruster was the first ion engine to be used for primary spacecraft propulsion in the Deep Space One (DS1) mission, validating ion thruster technology maturity for space flight. With a design lifetime of 8,000 hours, the NSTAR ion thruster accumulated 16,265 hours of operation in space and the flight spare accumulated 30,352 hours of continuous operation in ground-based testing. ${ }^{2,3}$

A key component of the NSTAR program is ground-based testing of engineering model thrusters (EM's or EMT's) for extended periods of time. The first wear test of an engineering model 30-cm NSTAR thruster was the full-power $(2.3-\mathrm{kW})$ 2000-hour wear test conducted at the NASA Glenn Research Center (GRC). The 2000-hour test, which did not employ a discharge cathode keeper, revealed extensive erosion of the two discharge cathodes used during the test. ${ }^{4}$ Subsequent 1000 -hour wear test and 8200-long duration test (LDT) employed a sacrificial keeper electrode demonstrating reduced discharge cathode erosion at an acceptable level $(\sim 60 \mu \mathrm{m} / \mathrm{khr}){ }^{5-7} \mathrm{An}$ Extended Life Test (ELT) of the NSTAR DS1 flight spare thruster, conducted at the Jet Propulsion Laboratory (JPL), revealed extensive keeper erosion that has yet to be fully explained. There is a lack of understanding of the discharge cathode assembly (DCA) erosion phenomena in ring-cusp ion thrusters. Engineering solutions, such as thicker keeper electrodes and more exotic keeper materials, may not be sufficient to achieve desired ion thruster lifetimes for future missions requiring several tens of thousands of hours. ${ }^{8,9}$ A detailed understanding of the discharge plasma environment in ion thrusters will lead to better discharge designs and DCA erosion mitigation methods.

The successful demonstration of the NSTAR ion engine provides an off-the-shelf 2.3-kW ion engine suitable for discover class NASA missions. Several missions under consideration for the exploration of the Solar System have identified higher-power, higher-throughput $5 / 10-\mathrm{kW}$ ion propulsion systems as a requirement for feasible missions. ${ }^{10}$ For larger flagship-type missions, specifically robotic exploration of the outer planets using $25-\mathrm{kW}$-class solar-powered electric propulsion, NASA GRC has led a team to develop the next generation ion thruster. The 40$\mathrm{cm}$ xenon ion engine, termed NASA's Evolutionary Xenon Ion Thruster (NEXT) was selected in 2002 for technology development as part of the Next Generation Electric Propulsion Project (NGEP). ${ }^{11,12}$

Several investigations have been underway to diagnose discharge cathode erosion in the 30-cm NSTAR ion thruster involving Laser-Induced Fluorescence (LIF) measurements, measurement of energetic ions near the DCA, and (concurrent with this investigation) electrostatic probing of the discharge chamber and discharge cathode. ${ }^{13-20}$ High-resolution discharge plasma characterization of the near-DCA region of a 30-cm NSTAR thruster has been accomplished utilizing a high-speed probe positioning system. ${ }^{21-24}$ Mapping the internal plasma structure of the 30$\mathrm{cm}$ ion engine downstream of the DCA permitted the elimination of the potential hill theory as an explanation of the DCA erosion and illustrated a free-standing double layer plasma potential structure. The double layer is aligned with the axial magnetic field near the DCA and forms the transition between the low potential discharge cathode plume and the high potential bulk discharge plasma.

In an attempt to diagnose DCA erosion issues, an investigation of the discharge plasma structure of a $40-\mathrm{cm}$ NEXT ion thruster has been initiated. To the author's knowledge this is the only internal investigation on a NEXT ion thruster to date. The purpose of this experiment is to obtain electron energy distribution functions (EEDF's) in the discharge chamber of the 40-cm NEXT ion engine, focusing on three regions: near the DCA, the bulk discharge, and the transition region between the two. The measurement of the EEDF's will help to explain the measured electron temperature trends in the Langmuir probe investigation of the LM4 thruster. ${ }^{25}$ A secondary probe, located closer to the ion optics, offers additional valuable discharge chamber data. Determination of the discharge plasma environment permits evaluation of the DCA erosion mechanisms and estimation of the NEXT DCA erosion rate. ${ }^{26}$

\section{40-cm NEXT Ion Thruster}

The NEXT ion engine follows the "derated" approach of the NSTAR program to preserve the NSTAR design heritage. This design approach maintains low beam current densities, low component operating temperatures (specifically the permanent magnets), and reduces operating voltages that can accelerate wear mechanisms. To maintain low beam current densities while increasing throughput, an engine twice the beam area of the NSTAR thruster was designed - beam diameter increased from 28-cm (NSTAR) to 40-cm (NEXT) doubles the beam extraction area. The higher beam area provides higher-power capability while maintaining comparable current densities, temperatures, and operating voltages. An input power of 4.7-kW on the NEXT engine operates at the same voltages and beam current density as $2.3-\mathrm{kW}$ on the NSTAR engine. The NEXT engine is expected to yield the same operating lifetime while producing twice the thrust. 


\section{A. NEXT Engine Design}

The major components of the NEXT engine are designed based upon the NSTAR thruster. These include a non-ferrous spun-form discharge chamber, comparable discharge and neutralizer hollow cathode designs, similar electrical isolation techniques, analogous flake retention mesh, and dished two-grid ion-optics system. Improvements beyond NSTAR include: improved beam flatness via magnetic field design, a compact propellant isolator, increased beam voltage (up to $1800 \mathrm{~V}$ ), and advanced ion optics design. The discharge and neutralizer cathodes have increased dimensions to accommodate the elevated current required along with some minor modifications. Performance testing of two engineering model thrusters and a laboratory model thruster exhibit peak specific impulse and thrust efficiency ranges of $4060-4090$ seconds and $0.68-0.69$, respectively, at the $6.1 \mathrm{~kW}$ power point. ${ }^{27}$ A 2000 hour wear test has been conducted on Engineering Model 1 (EM1) at a thruster input power of $6.9 \mathrm{~kW}$ demonstrating specific impulse, thrust efficiency, and calculated thrust of $4110 \mathrm{~s}, 0.694$, and $237 \mathrm{mN}$ respectively. ${ }^{28}$ A longduration test of an EM thruster at NASA GRC has begun at the time of this publication and is expected to exceed 8000 hours of operation. At this date, the construction of a prototype model thruster is ongoing. ${ }^{29}$

\section{B. Laboratory Model 4 (LM4) 40-cm NEXT Ion Thruster}

The fourth-built, 40 -cm laboratory model NEXT ion engine, referred to as LM4, was designed, fabricated, and assembled at NASA GRC. The engine design was modified with the intention of conducting electrostatic probe measurements and future Laser-Induced Fluorescence (LIF) measurements, inside the discharge chamber for normal engine operation with beam extraction. The LM4 variant is functionally equivalent to the NASA NEXT EM design with several incorporated features to facilitate discharge plasma interrogation and LIF characterization. The principal modifications between the LM4 and the EM thrusters include:

- Rotation of the gimbal and ion optics mounting by 45 degrees.

- Fabrication of a purely cylindrical plasma shield to facilitate access to the discharge chamber and reduce the complexity of the discharge plasma containment design.

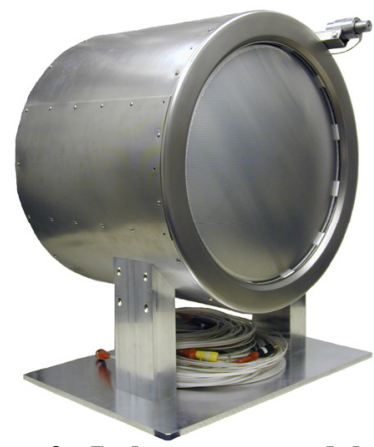

Figure 2. Laboratory model 4 (LM4) 40-cm NEXT ion thruster.

- Anode fabrication from welded stainless steel sheet opposed to the NEXT EM thruster spun stainless steel anode.

- Incorporation of mechanical cathodes (employing machined Macor to isolate the cathode common, cathode heater, and cathode keeper) for the LM4 as opposed to the brazed cathode assemblies of the NEXT EM thrusters.

- Incorporation of a machined stainless steel optics mounting ring assembly instead of the ion optics stiffener ring mounting assembly of the EM's.

- Iso-mica optics spacer and macor tabs used to hold the grids in place and set the grid gap.

- Modification of the high-voltage propellant isolator design.

- Modification of the neutralizer mounting (at 45 degrees).

These design changes have a negligible effect on the operation of LM4 when compared to the 40-cm Engineering Model thrusters (EM's), as verified by magnetic field mappings and engine performance testing. ${ }^{30}$

\section{LM4 Engine Modifications}

Following confirmation of comparable performance to the EM's from characterization testing, the LM4 anode is modified for electrostatic probe access to the discharge chamber via slots in the side of the anode, shown in Figure 3. Slots are cut into the anode side and top for probe access and alignment of the probe to the discharge cathode assembly, respectively. Flanges are mounted to the slots permitting axial motion perpendicular to the flange opening and allowing easy transition between probe interrogation hardware and future LIF windows. The LM4 modifications and added hardware components are illustrated in Figure 3. 

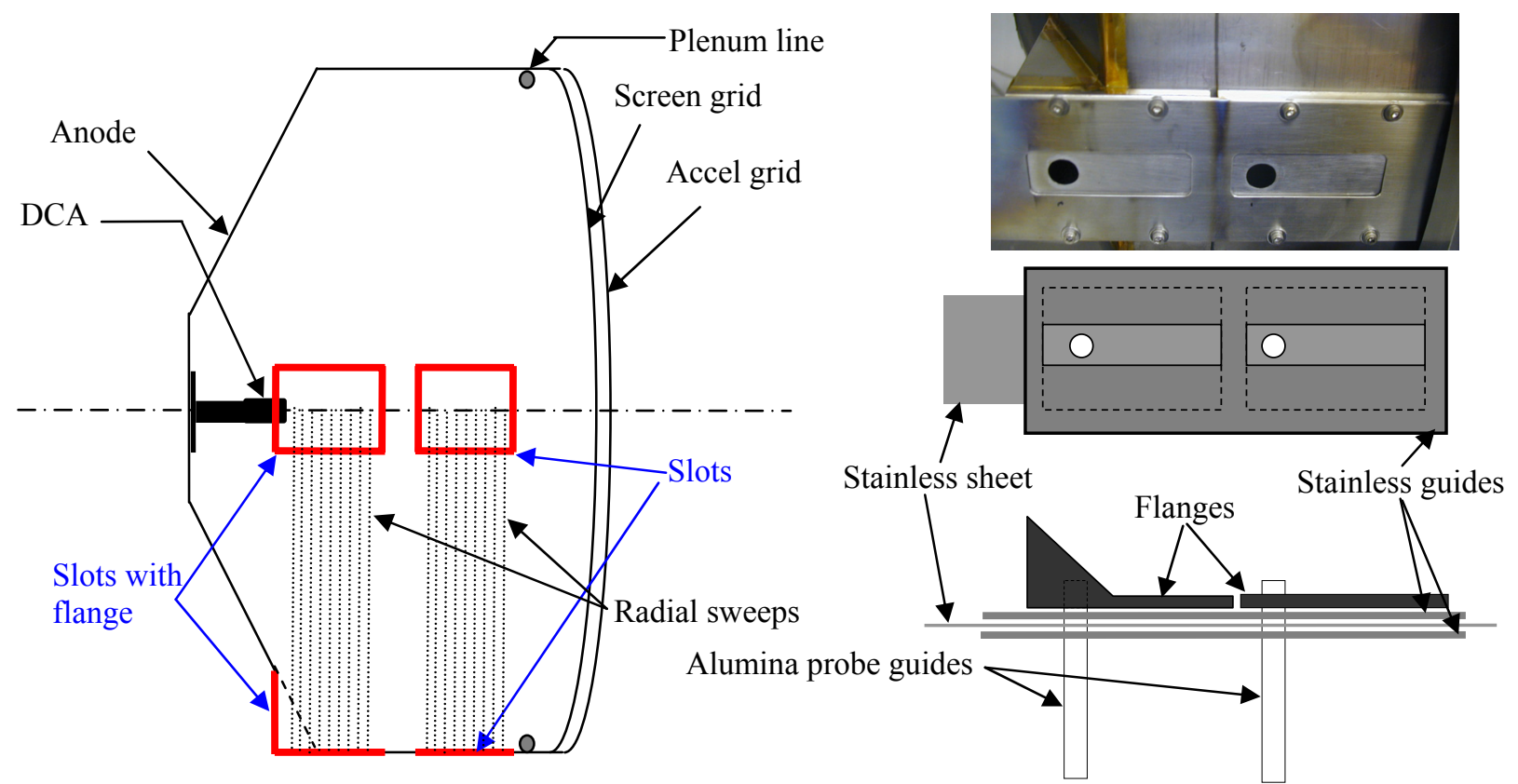

Figure 3. LM4 discharge interrogation modifications. Schematic of the slots and mounting flanges on anode (left). The discharge plasma containment hardware is illustrated on the right.

\section{Experimental Apparatus}

\section{A. Vacuum Testing Facility}

The LM4 discharge chamber investigations are conducted in the Plasmadynamics and Electric Propulsion Laboratory (PEPL) cylindrical 6-m-diameter by 9-m-long stainless steel-clad Large Vacuum Test Facility (LVTF). With seven cryopumps activated, surrounded by liquid nitrogen cooled baffles, the LVTF maximum pumping speed is $240,000 \mathrm{l} / \mathrm{s}$ on xenon $(500,000 \mathrm{l} / \mathrm{s}$ on air). Pressure measurements, from a Varian model UHV-24 nude ion gauge with a Varian UHV senTorr vacuum gauge controller mounted on the LVTF wall, are corrected for xenon using the known base pressure on air, the indicated gauge pressure, and a correction factor of 2.87 for xenon according to, ${ }^{31}$

$$
P_{c}=\frac{P_{i}-P_{b}}{2.87}+P_{b}
$$

The LVTF is operated with either four or seven cryopumps depending upon ion thruster operating condition. With four cryopumps, the facility pumping speed is $140,000 \mathrm{l} / \mathrm{s}$ on xenon with a base pressure typically $4 \times 10^{-7}$ Torr. The LVTF can maintain a pressure in the low $10^{-6}$ Torr range during operation of the LM4 at low-to-mid power with the four cryopumps activated. To reduce the ingested flow into the discharge chamber, the LM4 testing is conducted with four cryopumps for low-to-mid power and with seven cryopumps for higher power. With seven cryopumps activated, the LVTF base pressure is $2 \times 10^{-7}$ Torr. At the LM4 highest power condition permissible, the corrected background pressure is $2.8 \times 10^{-6}$ Torr for a total xenon flow rate of $5 \mathrm{mg} / \mathrm{s}$.

\section{B. High-speed Probe Positioning System (HARP)}

A linear motor assembly provides accurate direct linear motion of the probe with minimal discharge cathode plume residence times. The HARP system, shown in Figure 4, is a three-phase Trilogy 210 brushless dc servo motor consisting of a linear "U"-shaped magnet track and a "T"-shaped coil moving on a set of linear tracks. The linear encoder provides positioning resolution to $5 \mu \mathrm{m} .^{32}$ A Pacific Scientific SC950 digital, brushless servo drive controls the motor. The HARP is a linear table with a $559 \mathrm{~mm}$ stroke length. The HARP is capable of moving small probes at speeds above $250 \mathrm{~cm} / \mathrm{s}$ with acceleration rates above $7 \mathrm{~g}$ 's. The entire HARP table is enclosed in a stainless steel 
shroud with a graphite outer skin. Residence times of the probe inside the discharge cathode plume are kept under 100 msec to minimize probe heating and discharge plasma perturbation. The HARP system was initially designed for internal discharge channel electrostatic probe measurements on Hall thrusters. ${ }^{14,32-36}$ The HARP system is minimally modified for $30-\mathrm{cm}$ NSTAR discharge chamber characterization and the near DCA 40-cm NEXT discharge plasma characterization. ${ }^{21-24}$ The primary modifications include the probe mounting on-axis with the HARP and optimization of the control variables to achieve the desired sweep for trajectory given the HARP velocity and acceleration requirements.

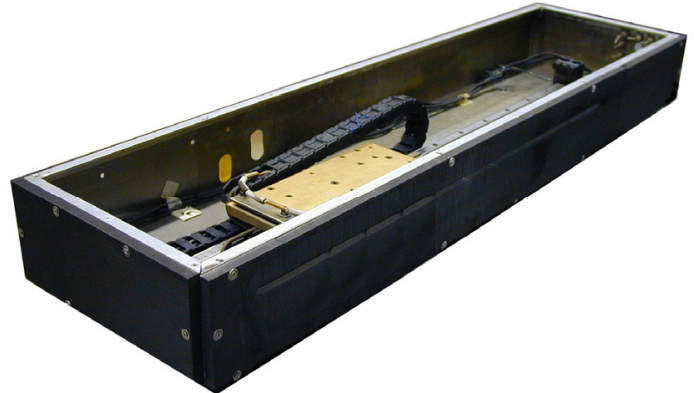

Figure 4. High-speed Axial Reciprocating Probe (HARP) positioning system.

\section{Axial Movement of Probe}

A single-axis Aerotech ATS62150 linear ball screw translation table provides axial movement of the thruster relative to the probe. The Aerotech table has a travel length of $1.5 \mathrm{~m}$ with an accuracy of $\pm 2.5 \mu \mathrm{m}$. A Renco RCM21 encoder provides precision measurement of the position of the thruster with a resolution of $5 \mu \mathrm{m}$ and a frequency response of $200 \mathrm{kHz}$. The orientation of hardware and probes is illustrated in Figure 5. Two staggered electrostatic probes are inserted into the LM4 discharge plasma in the radial direction. The upstream probe characterizes the near-DCA region, while the downstream probe characterizes the near-optics region. The near-DCA mapping begins $\sim 1.5 \mathrm{~mm}$ downstream of the discharge keeper face with an axial resolution of $1 \mathrm{~mm}$. Each probe is activated individually, with the dormant probe floating. When actuated, the probe extends to the thruster centerline then returns to the starting location recessed inside the translating alumina tube. When not in use, the probes are recessed in the guiding alumina tube protecting the probes and reducing probe perturbations on the LM4 thruster operation.

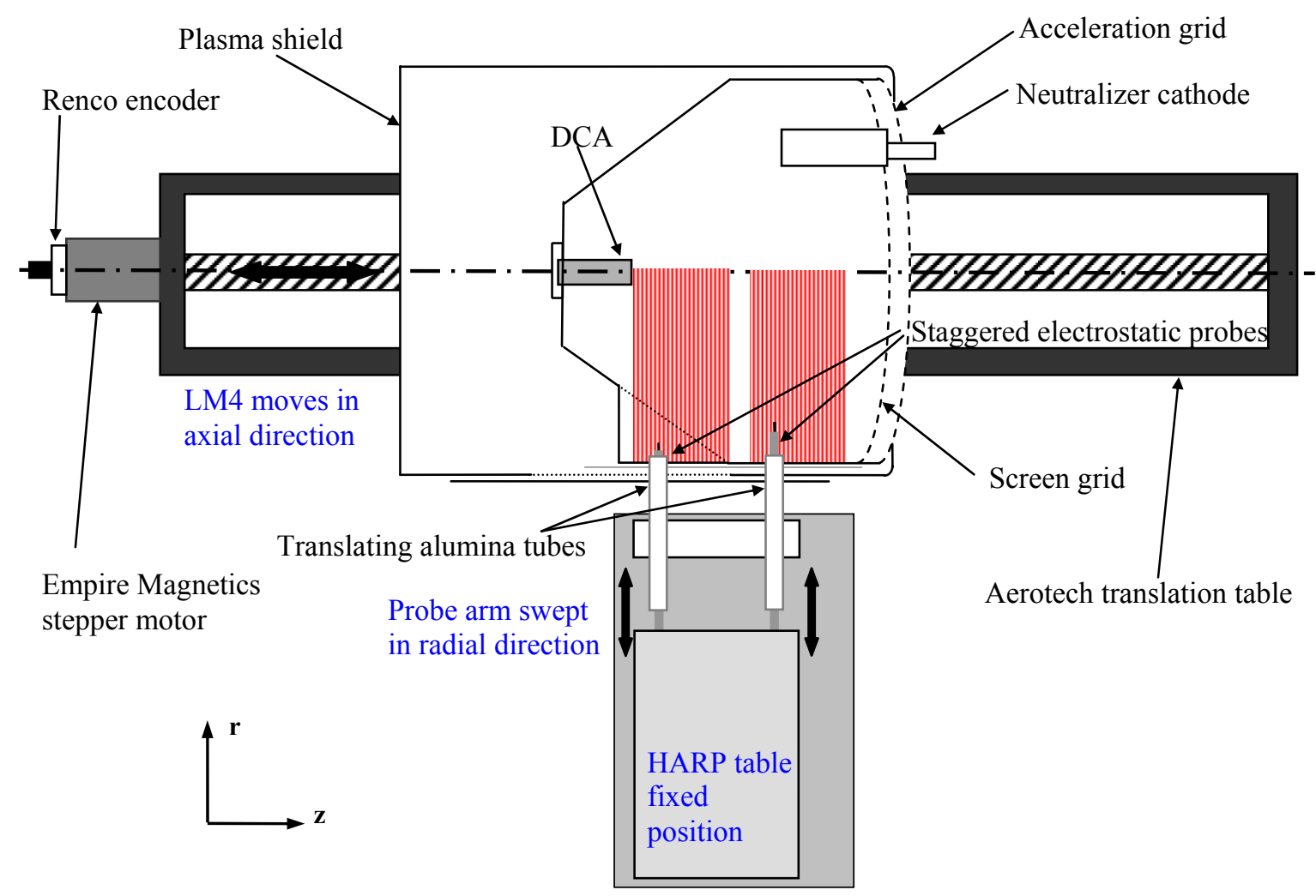

Figure 5. LM4 and HARP orientation with the translating table permitting axial movement. 


\section{Langmuir Probe Diagnostic}

Electrostatic probes have been extensively used to measure plasma parameters since their inception. Langmuir probes, named after the pioneering work performed by Irving Langmuir and collaborators, are one of the oldest and widely used probes in plasma characterization..$^{37,38}$ The single Langmuir probe consists of a single electrode connected to an external electrical circuit allowing variation of the probe voltage, $\mathrm{V}$, with respect to the local plasma. Measurement of the probe bias voltage and collected current are plotted giving the current-voltage characteristic (I-V curve). Langmuir probes can be used to determine the electron energy distribution function (EEDF) at the point of interest. Two different techniques are used in this investigation: the Druyvesteyn method (or second derivative method) and the harmonic method (or ac method).

\section{A. Druyvesteyn or Second Derivative Method}

Druyvesteyn was the first to utilize the fact that the second derivative of the electron current with respect to the probe bias voltage is proportional to the electron energy distribution function (EEDF) if the velocity distribution is isotropic, given in Eq. 4:

$$
f_{E}(E)=\frac{-4}{A_{p} e^{2}}\left(\frac{m_{e}\left(V_{\text {plasma }}-V\right)}{2 e}\right)^{\frac{1}{2}} \frac{d^{2} I_{e}(V)}{d V^{2}} \quad \mathrm{~V}_{\mathrm{p}}<0
$$

where $\mathrm{E}$ is in $\mathrm{eV}$ and the $\mathrm{EEDF}, \mathrm{f}_{\mathrm{E}}(\mathrm{E})$, is in $\mathrm{m}^{-3} \mathrm{eV}^{-1}$. If the EEDF is Maxwellian, Eq. 4 can be integrated twice to give the theoretical electron current as a function of probe voltage below the plasma potential.

$$
I_{e}(V)=\left(e A_{p} N \sqrt{\frac{k T_{e}}{2 \pi m_{e}}}\right) \exp \left(\frac{-e\left(V_{\text {plasma }}-V\right)}{k T_{e}}\right)
$$

Unfortunately, Eq. 4 is difficult to calculate because of the inaccuracies introduced by taking the second derivative of an experimentally measured I-V characteristic. Data smoothing and sophisticated data analysis techniques are often utilized to reduce the introduced error. To assist in error reduction further, multiple I-V traces are averaged to remove noise in the characteristics.

\section{B. Harmonic or AC Method}

Calculation of the EEDF utilizing the Druyvesteyn method is difficult owing to the amplification of noise when differentiating the original I-V characteristic. The harmonic method allows direct electronic determination of the second derivative. In the harmonic method, a small ac signal is superimposed on the dc probe voltage. The dc current rises by a small amount, which is proportional to the second derivative. A Taylor expansion of the modulated electron current reveals that the second derivative term is proportional to the term containing the second harmonic of the small input ac signal, illustrated in Eq. $6 .^{39,40}$

$$
\begin{gathered}
I_{e}\left(V_{p}+a \cdot \sin (\varpi t)\right)=\left[I_{e}+\frac{a^{2}}{4} I_{e}^{\prime \prime}+\frac{a^{4}}{64} I_{e}^{\prime \prime \prime \prime}+\ldots\right] \quad \mathrm{dc} \text { component } \\
+\left[a I_{e}^{\prime}+\frac{a^{3}}{8} I_{e}^{\prime \prime \prime}+\ldots\right] \sin (\varpi t) \\
-\left[\frac{a^{2}}{4} I_{e}^{\prime \prime}+\frac{a^{4}}{48} I_{e}^{\prime \prime \prime \prime}+\ldots\right] \cos (2 \varpi t) \quad \text { undistorted ac component } \\
-\left[\frac{a^{3}}{24} I^{\prime \prime \prime}+\ldots\right] \sin (3 \varpi t)+\left[\frac{a^{4}}{192} I_{e}^{\prime \prime \prime \prime}+\ldots\right] \cos (4 \varpi t)+\text { higher order harmonics }
\end{gathered}
$$


For a sufficiently low amplitude ac signal $\left(\mathrm{a}<<\mathrm{V}_{\mathrm{p}}\right)$, the increase of the dc current can be approximated by Eq. 7 . Since $\mathrm{I}_{\mathrm{p}}{ }^{\prime \prime} \approx \mathrm{I}_{\mathrm{e}}$ " for sufficiently negative probe potentials, the second derivative of $\mathrm{I}_{\mathrm{e}}$ can be determined directly from the second harmonic. A lock-in amplifier is utilized to obtain the second harmonic, which is related to the second derivative of the electron current by:

$$
\Delta I_{e}=\frac{1}{4} a^{2} I_{e}^{\prime \prime}\left(V_{p}\right)
$$

\section{Langmuir Probe Electrode}

The Langmuir probe design consists of 0.13 or 0.18 -mm-diameter cylindrical tungsten electrode with $\sim 2 \mathrm{~mm}$ of exposed length, illustrated in Figure 6. A large length-to-diameter ratio minimizes end effects. The electrode is held inside a double-bore piece of $99.8 \%$ pure alumina epoxied to a larger double-bore piece of $99.8 \%$ pure alumina. The ceramic probe material and tungsten filament are necessitated by the high temperature discharge chamber environment. The total probe length is approximately $0.5 \mathrm{~m}$. After the probes are constructed, each is inspected under magnification to ensure cylindrical geometry. The probe tip electrodes are measured with a digital caliper and double checked under magnification.

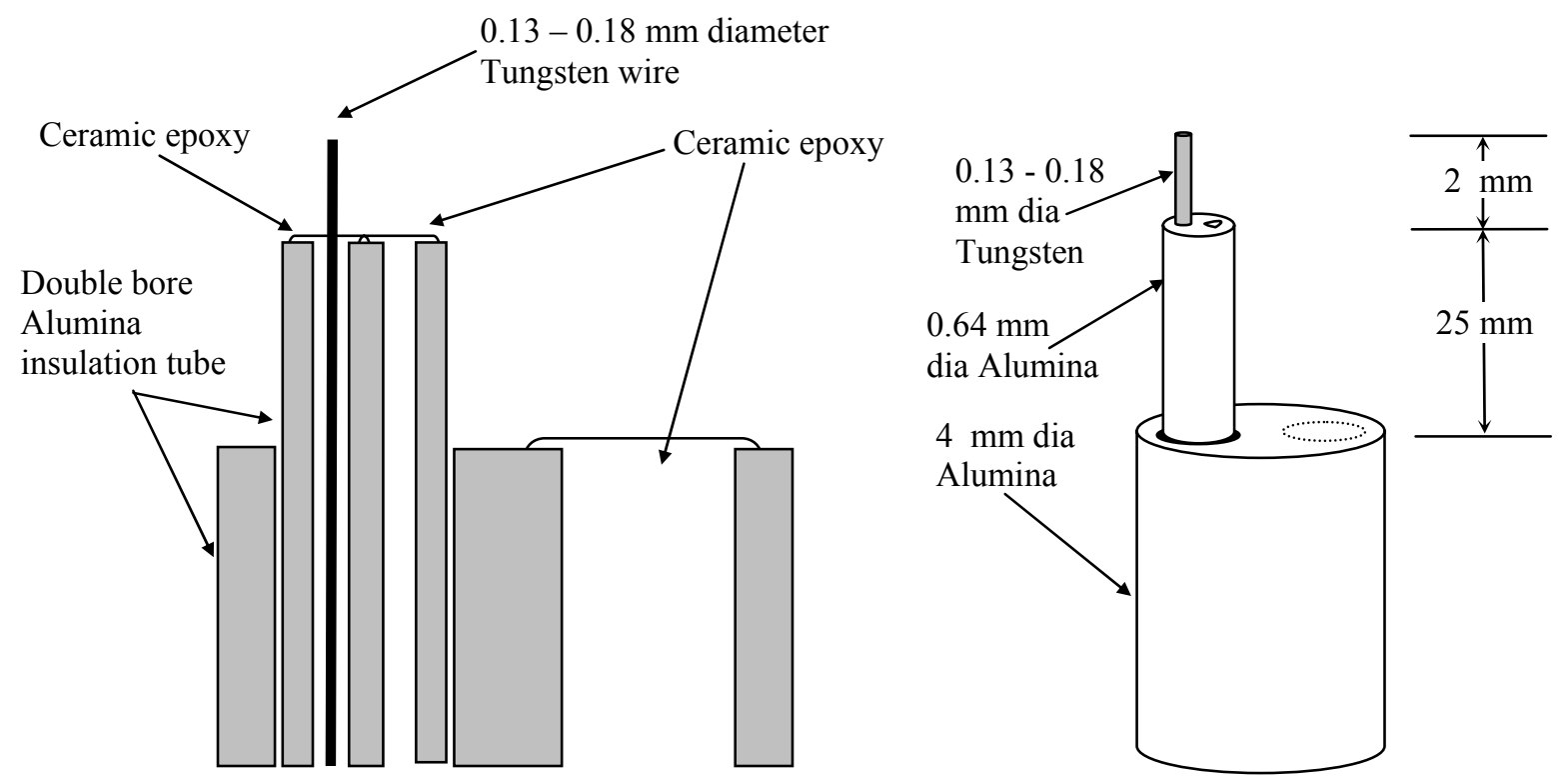

Figure 6. Langmuir probe tip design illustrating the components and physical dimensions.

\section{EEDF Circuitry}

For the Druyvesteyn (second derivative) method, the probe is connected to a floating Kepco BOP 100-2M programmable bipolar power supply that is driven by a floating signal generator. The bipolar power supply and generator are used to rapidly sweep the bias voltage permitting continuous I-V curves, facilitating differentiation. The Langmuir probe is biased with respect to the discharge cathode. A function generator provides a ramping voltage signal at $200 \mathrm{~Hz}$ with the resulting bipolar sweep from +30 to -40 volts with respect to discharge cathode common, covering both electron and ion saturation regions. The outputs from the isolation amplifiers are sent to an oscilloscope where they are stored on a PC via a National Instruments GPIB interface.

The harmonic (ac) method utilizes an additional function generator to supply the ac signal, which is superimposed on the dc ramping bias voltage. The small ac signal has an amplitude of $4 \mathrm{~V}$ pk-pk and a frequency of $2 \mathrm{kHz}$. The dc ramping voltage has a range of +32 to -24 volts (referenced to discharge cathode common) and a frequency of $5 \mathrm{~Hz}$. A Stanford Research Systems SR810 DSP lock-in amplifier is used to measure the second harmonic of the probe current signal. The SRS SR 810 DSP has a full scale sensitivity of $2 \mathrm{nV}$ and a frequency range of $1 \mathrm{mHz}$ to $102 \mathrm{kHz}$. The relative phase error is $<0.01^{\circ}$ and time constants as low as $10 \mu \mathrm{s}$. A summing circuit combines the two signals that are sent to the bipolar supply to set the probe bias voltage. The harmonic EEDF is 
applied to the LM4 engine without beam extraction due to the number of electronics involved in the experimental setup that would have to float.

The isolated voltage and current measurement circuit is a modified version of the Langmuir probe circuit used in previous LM4 testing. ${ }^{25}$ The circuit is built around two Analog Devices AD210 wide bandwidth isolation amplifiers, capable of handling up to 2500 volts of common mode voltage, providing an input impedance of $10^{12} \Omega$, and a fullpower bandwidth of $20 \mathrm{kHz}$. The low-impedance output ( $1 \Omega$ maximum) is connected to a Tektronix TDS 3034B digital oscilloscope that acquires the I-V data and saves it to a computer. Figure 7 illustrates the electronics and circuitry used to capture the EEDF's. All connections extending outside the vacuum chamber are made using highvoltage $(5 \mathrm{kV})$ SHV coaxial cables and feedthroughs.

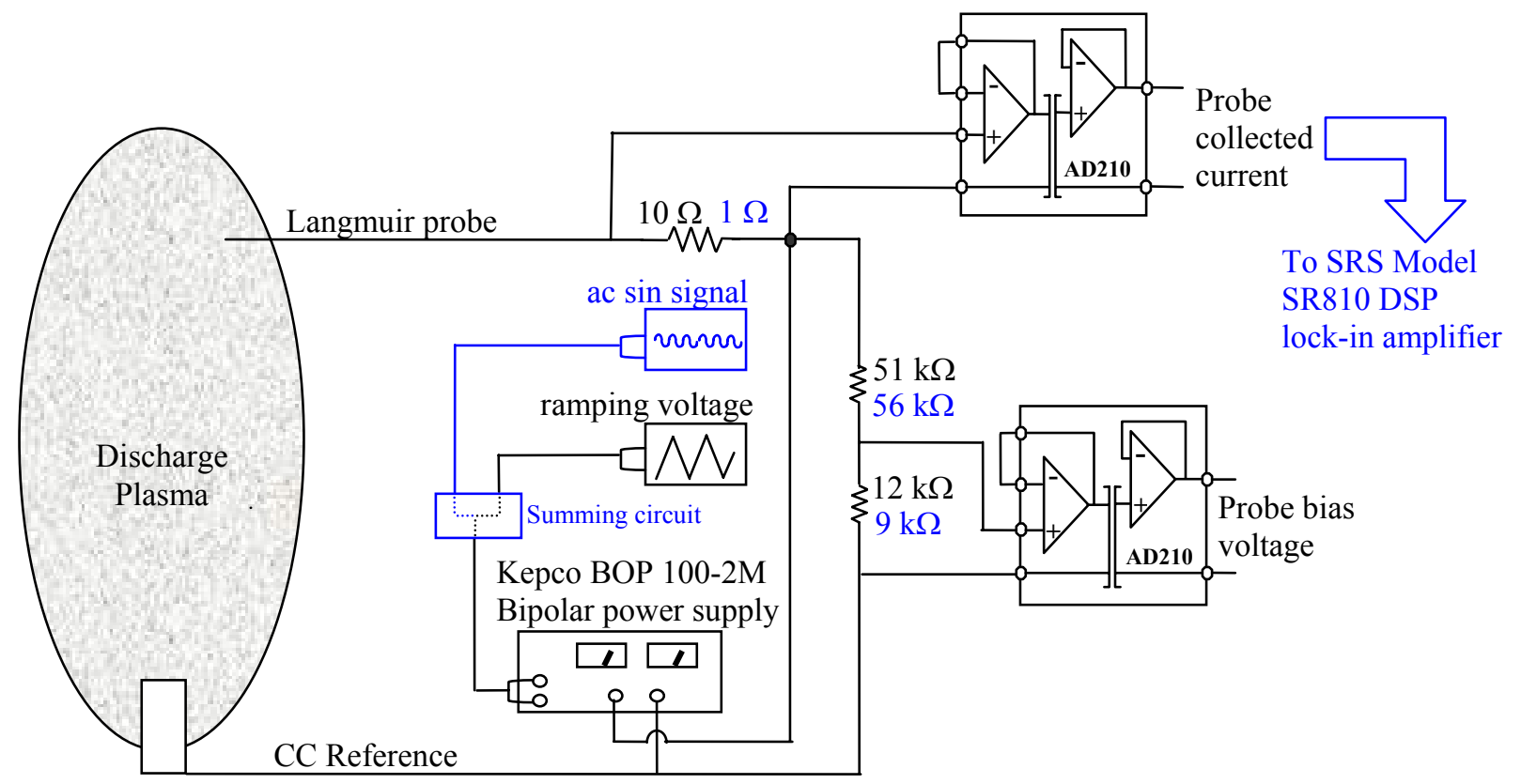

Figure 7. Druyvesteyn (second derivative) and Harmonic (ac) methods circuit and electronics. The additional components and different resistor sizes for the harmonic method are indicated in blue.

\section{E. Data Analysis}

The scientific graphing package Igor is used to analyze the data. Two data analysis methods are used for the corresponding EEDF measurement methods.

\section{Druyvesteyn Method Analysis}

The EEDF's are obtained from the second derivative of the averaged I-V characteristics. The averaging of $>20$ I$\mathrm{V}$ pairs greatly reduces the noise in the current-voltage curve as illustrated in Figure 8, and serves as the starting point for the Druyvesteyn data analysis. The resulting averaged I-V curve contains roughly 200 data pairs.

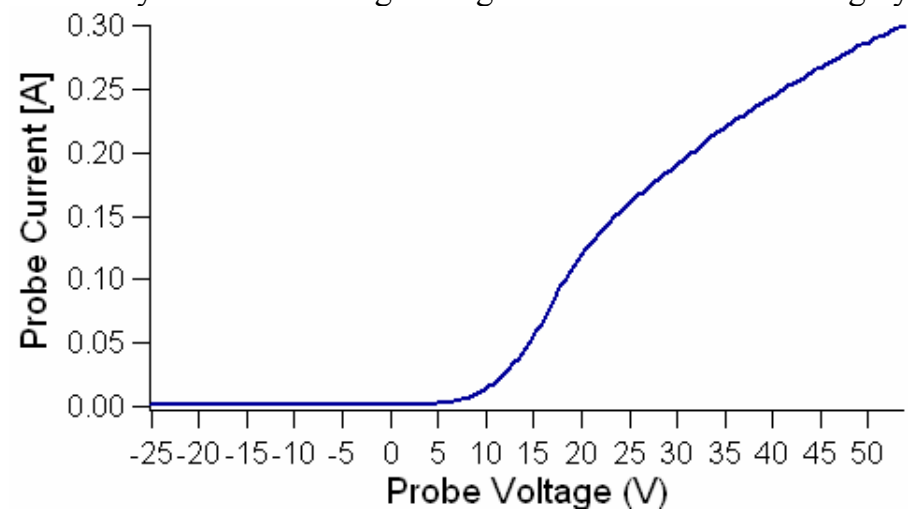

Figure 8. Sample averaged I-V characteristic at the closest axial location along centerline location using the floating bipolar supply and function generator (No smoothing applied). 
Druyvesteyn has shown that the EEDF is proportional to the second derivative of the probe current:

$$
f_{E}(E) \propto \sqrt{E} \cdot \frac{d^{2} I_{p}}{d V_{p}^{2}}
$$

where $\mathrm{E}=\left(\mathrm{V}_{\text {plasma }}-\mathrm{V}\right)$. The local plasma potential at the location of the EEDF measurement is determined from floating emissive probe results on the LM4 thruster. ${ }^{26}$ A 5-point box smoothing is applied to the I-V curve to reduce noise. After the numeric first derivative, an 11-point box smoothing algorithm is applied to the resultant I'-V curve before the second derivative is applied. After the second numeric differentiation is applied, the resultant I''-V curve is again smoothed in the same fashion as the first derivative. The second derivative is multiplied by the square root of the energy with respect to the local plasma potential giving the EEDF. Finally the EEDF is normalized by the area under the curve and multiplied by the local plasma number density measured from single Langmuir probe giving the electron energy distribution in the plasma. ${ }^{25}$

\section{Harmonic Method Analysis}

The second harmonic of the probe current, measured by the lock-in amplifier, is proportional to I'. Ten measurements are made at each spatial location and the signals are averaged to remove the noise in the measurement. The output of the lock-in amplifier, $\mathrm{A}(\mathrm{E})$, is related to the electron energy distribution function by:

$$
f(E)=\sqrt{E} A(E)
$$

In Eq. 9, $\mathrm{E}$ is the voltage with respect to local plasma potential. Similar to the Druyvesteyn method data analysis, the distribution function calculated by Eq. 9 is normalized and the result multiplied by the local plasma number density giving the electron energy distribution in the plasma.

\section{F. Magnetic Field Effects}

The magnetic field can affect Langmuir probe results by altering the I-V characteristic. The primary effect of the magnetic field is to confine electrons to spiral along the magnetic field lines. As a result, sheath structures around probes are no longer symmetric and can become oblong. The magnetic field can lead to EEDF anisotropy. The primary effect of the magnetic field is to confine electrons within a Larmor radius and depress diffusion across the magnetic field. Passoth determined that EEDF anisotropy depends upon the ratio $\mathrm{B} / \mathrm{p}_{\mathrm{o}}$, where $\mathrm{p}_{\mathrm{o}}$ is the pressure in the containment vessel (in this case the discharge chamber). ${ }^{41}$ It has been shown experimentally that EEDF anisotropy is negligible for $\mathrm{B} / \mathrm{p}_{0} \leq 2.5 \times 10^{6} \mathrm{G} /$ Torr. $^{42}$

The LM4 thruster has a maximum magnetic field (B), in the bulk discharge and near-DCA regions, occurring near the DCA along centerline. The maximum magnitude of the magnetic field in the near-DCA regions investigated is several tens of Gauss and the pressures in the discharge chambers of the engines are estimated to be $\sim 10^{-4}$ Torr. The LM4 measurements made near the cusps at the anode can reach magnetic field magnitudes on the order of a few hundred Gauss. The value of $\mathrm{B} / \mathrm{p}_{\mathrm{o}}$ near the DCA is $1 \times 10^{6}$, and for the worst case, near the anode magnetic field cusps, is $2 \times 10^{6}$; therefore no substantial anisotropy (due to the magnetic field) in the EEDF is expected for the spatial locations interrogated.

\section{G. Error Analysis}

The primary error in the Druyvesteyn method results from noise in the measured signal that is amplified when taking derivatives. This introduces substantial error to the EEDF calculated using this method even when using advanced smoothing techniques and averaging multiple I-V data sets. The result of over-smoothing the data and numeric derivatives are to remove small voltage-spanning distribution features. The amount of smoothing applied to the current and resultant derivatives is minimized while producing smooth EEDF's.

Most of the uncertainty in the harmonic EEDF measurement is associated with higher-order derivatives that contribute to the signal detected by the lock-in amplifier. The small superimposed ac signal may also penetrate into the plasma causing oscillations. The estimated error in the harmonic EEDF measurement is approximately $8 \%$. The high-frequency ac amplitude used is 4 volts pk-pk to achieve a satisfactory signal-to-noise ratio. This amplitude is higher than desired and may smooth out EEDF structures whose voltage width is smaller than this amplitude. Because this method is not easily implemented for engine operation with beam extraction, the measured EEDF's 
may be different than those for flight-like operation. It has been observed that the discharge electron temperatures without beam extraction are decreased compared to operation with a beam. ${ }^{25}$ The electron temperature and EEDF are intimately related, thus it is expected that the discharge-only (no beam extraction) EEDF's will differ from those observed with beam extraction.

\section{H. Operating Conditions Investigated}

The LM4 thruster EEDF investigation is performed over a variety of thruster operating conditions limited at high-power by the beam and discharge power supplies. The investigation covers a range of conditions from low-tomid power. In addition to the nominal operation with beam extraction, the thruster is operated with discharge-only and with the discharge keeper shorted to discharge cathode common. The Druyvesteyn (second derivative) method EEDF (DEEDF) operating conditions are listed in Table 1. The harmonic (ac) method EEDF (HEEDF) operating conditions are illustrated in Table 2. The mapping of the electron energy distribution function illustrates negligible sensitivity to thruster power level. Due to the large number of EEDF's for each operating condition (9,240 EEDF's for each probe), only select profiles of the discharge chamber EEDF's are presented. A comprehensive display of the data collected can be found in Reference 30.

Table 1. LM4 Druyvesteyn Electron Energy Distribution Function (DEEDF) nominal Thruster Operating Conditions (TOC Levels), Discharge-only Level (DL), and reference NEXT self-assigned Throttling Levels (TH Levels).

\begin{tabular}{|c|c|c|c|c|c|c|c|c|c|c|c|c|c|c|c|}
\hline & $\mathrm{TH}$ & Vs & $\mathrm{Jb}$ & $\mathrm{Va}$ & $\mathrm{Ja}$ & Vdc & $\mathrm{Jdc}$ & Vnk & Jnk & $\begin{array}{l}\text { Main } \\
\text { Flow }\end{array}$ & $\begin{array}{l}\text { D.C. } \\
\text { Flow }\end{array}$ & $\begin{array}{l}\text { Neut } \\
\text { Flow }\end{array}$ & $\begin{array}{c}\text { Vck- } \\
\text { cc }\end{array}$ & $\mathrm{Vg}$ & Pressure \\
\hline & Level & {$[\mathrm{V}]$} & {$[\mathrm{A}]$} & {$[\mathrm{V}]$} & {$[\mathrm{mA}]$} & {$[\mathrm{V}]$} & {$[\mathrm{A}]$} & {$[\mathrm{V}]$} & {$[\mathrm{A}]$} & [sccm] & {$[\mathrm{sccm}]$} & {$[\mathrm{sccm}]$} & {$[\mathrm{V}]$} & [V] & [Torr] \\
\hline \multirow{4}{*}{$\begin{array}{ll}0 & 0 \\
0 & 0 \\
0 & 0 \\
0 & 0 \\
1 & 0 \\
0\end{array}$} & TH 34 & 1567 & 3.10 & -210.0 & 10.50 & - & 17.68 & - & 3.00 & 43.47 & 4.54 & 4.01 & - & - & - \\
\hline & DEEDF TOC 34' & 1501 & 3.10 & -210.1 & 18.47 & 23.85 & 17.54 & 13.29 & 3.00 & 43.5 & 4.48 & 4.01 & 4.68 & -12.35 & $3.5 \mathrm{E}-06$ \\
\hline & TH 20 & 1567 & 2.00 & -210.0 & 6.80 & - & 14.12 & - & 3.00 & 25.79 & 3.87 & 2.50 & - & - & - \\
\hline & DEEDF TOC 20' & 1500 & 2.00 & -210.1 & 8.43 & 24.51 & 13.95 & 13.51 & 3.00 & 24.9 & 3.79 & 2.50 & 1.94 & -12.41 & 2.6E-06 \\
\hline \multirow{10}{*}{ 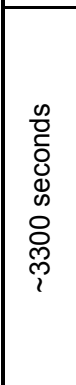 } & TH 32 & 1179 & 3.10 & -200.0 & 10.50 & - & 18.63 & - & 3.00 & 43.47 & 54 & & & & \\
\hline & DEEDF TOC 32 & 1179 & 3.10 & -200.1 & 18.68 & 24.20 & 18.03 & 13.25 & 3.00 & 43.4 & 4.48 & 4.01 & 4.70 & -12.59 & $3.5 \mathrm{E}-06$ \\
\hline & TH 18 & $\overline{1179}$ & 2.00 & -200.0 & 6.80 & - & 14.72 & - & 3.00 & 25.79 & 3.87 & 2.50 & - & - & - \\
\hline & DEEDF TOC 18a & 1179 & 2.00 & -200.4 & 8.36 & 24.79 & 14.04 & 13.99 & 3.00 & 25.0 & 3.85 & 2.50 & 2.31 & -12.69 & $2.5 \mathrm{E}-06$ \\
\hline & DEEDF TOC $18 \mathrm{~b}$ & 1179 & 2.00 & -200.1 & 8.43 & 24.83 & 14.10 & 13.63 & 3.00 & 24.9 & 3.79 & 2.50 & 2.19 & -12.34 & $2.6 \mathrm{E}-06$ \\
\hline & TH 8 & 1179 & 1.20 & -200.0 & 4.10 & - & 8.83 & - & 3.00 & 14.23 & 3.57 & 3.00 & - & - & - \\
\hline & DEEDF TOC 8a & 1180 & 1.20 & -200.0 & 4.14 & 25.75 & 8.85 & 13.92 & 3.00 & 14.6 & 3.82 & 3.20 & 3.41 & -12.21 & $2.0 \mathrm{E}-06$ \\
\hline & DEEDF TOC 8b & 1179 & 1.20 & -200.0 & 4.77 & 25.82 & 8.75 & 14.76 & 3.00 & 15.0 & 4.39 & 3.11 & 3.78 & -12.02 & $2.0 \mathrm{E}-06$ \\
\hline & $\begin{array}{l}\text { DEEDF TOC } 8 \\
\text { CK-CC shorted }\end{array}$ & 1179 & 1.20 & -200.1 & 5.10 & 25.81 & 8.72 & 15.24 & 3.00 & 15.0 & 4.39 & 3.11 & 0.00 & -11.71 & 2.0E-06 \\
\hline & DEEDF DL 8 & - & - & - & 23.00 & 23.75 & 8.74 & 15.90 & 3.00 & 14.3 & 3.63 & 3.11 & 7.40 & -1.55 & $2.0 \mathrm{E}-06$ \\
\hline \multirow{4}{*}{ 䓵 } & TH 3 & 650 & 1.20 & -144.0 & 4.10 & - & 9.54 & - & 3.00 & 14.23 & 3.57 & 3.00 & - & - & - \\
\hline & DEEDF TOC 3 & 650 & 1.20 & -144.0 & 4.52 & \begin{tabular}{|l|}
26.18 \\
\end{tabular} & 9.96 & \begin{tabular}{|l|}
14.42 \\
\end{tabular} & 3.00 & 14.5 & 3.63 & 3.11 & 2.85 & -12.45 & $2.0 \mathrm{E}-06$ \\
\hline & TH 0 & 275 & 1.00 & -500.0 & 3.40 & - & 7.99 & - & 3.00 & 12.32 & 3.52 & 3.00 & & - & - \\
\hline & DEEDF TOC 0 & 275 & 1.01 & -500.0 & 3.58 & 26.11 & 7.85 & 14.70 & 3.00 & 12.6 & 3.90 & 3.11 & 4.77 & -12.50 & 1.9E-06 \\
\hline
\end{tabular}


Table 2. LM4 Harmonic Electron Energy Distribution Function (HEEDF) nominal Discharge-only Levels (DL) and reference NEXT self-assigned Throttling Levels (TH Levels).

\begin{tabular}{|c|c|c|c|c|c|c|c|c|c|c|c|c|c|c|c|}
\hline & $\mathrm{TH}$ & Vs & $\mathrm{Jb}$ & $\mathrm{Va}$ & $\mathrm{Ja}$ & $\mathrm{Vdc}$ & $\mathrm{Jdc}$ & Vnk & Jnk & $\begin{array}{l}\text { Main } \\
\text { Flow }\end{array}$ & $\begin{array}{l}\text { D.C. } \\
\text { Flow }\end{array}$ & $\begin{array}{l}\text { Neut } \\
\text { Flow }\end{array}$ & $\begin{array}{l}\text { Vck- } \\
\text { cc }\end{array}$ & $\mathrm{Vg}$ & Pressure \\
\hline & Level & {$[\mathrm{V}]$} & {$[\mathrm{A}]$} & [V] & {$[\mathrm{mA}]$} & {$[\mathrm{V}]$} & {$[\mathrm{A}]$} & {$[\mathrm{V}]$} & {$[\mathrm{A}]$} & [sccm] & [sccm] & [sccm] & {$[\mathrm{V}]$} & {$[\mathrm{V}]$} & [Torr] \\
\hline \multirow{3}{*}{ 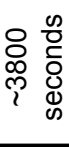 } & TH 34 & 1567 & 3.10 & -210.0 & 10.50 & - & 17.68 & - & 3.00 & 43.47 & 4.54 & 4.01 & - & - & - \\
\hline & HEEDF DL 34' & - & - & - & 38.70 & 22.44 & 17.59 & 16.08 & 3.00 & 37.9 & 4.31 & 4.01 & 6.25 & -0.68 & $3.1 \mathrm{E}-06$ \\
\hline & $\begin{array}{l}\text { HEEDF DL 34' } \\
\text { CK-CC shorted }\end{array}$ & - & - & - & 42.00 & 22.35 & 17.58 & 15.44 & 3.00 & 37.9 & 4.31 & 4.01 & - & -0.88 & $3.1 \mathrm{E}-06$ \\
\hline \multirow{5}{*}{ 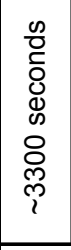 } & TH 18 & 1179 & 2.00 & -200.0 & 6.80 & - & 14.72 & - & 3.00 & 25.79 & 3.87 & 2.50 & - & - & - \\
\hline & HEEDF DL 18 & - & - & - & 29.00 & 22.80 & 14.01 & 18.02 & 3.00 & 21.1 & 3.58 & 2.50 & 6.42 & -0.88 & 2.1E-06 \\
\hline & TH 8 & 1179 & 1.20 & -200.0 & 4.10 & - & 8.83 & - & 3.00 & 14.23 & 3.57 & 3.00 & - & - & - \\
\hline & HEEDF DL 8 & - & - & - & 21.70 & 24.02 & 9.09 & 16.77 & 3.00 & 15.0 & 4.32 & 3.11 & 7.40 & -0.34 & $1.9 \mathrm{E}-06$ \\
\hline & \begin{tabular}{|l|} 
HEEDF DL 8 \\
CK-CC shorted
\end{tabular} & - & - & - & 23.62 & 24.00 & 9.10 & 16.71 & 3.00 & 15.0 & 4.32 & 3.11 & - & -0.23 & $1.9 \mathrm{E}-06$ \\
\hline \multirow{2}{*}{$\begin{array}{ll}3 & \bar{\phi} \\
0 & 3 \\
0 & 0 \\
0\end{array}$} & TH 0 & 275 & 1.00 & -500.0 & 3.40 & - & 7.99 & - & 3.00 & 12.32 & 3.52 & 3.00 & - & - & - \\
\hline & HEEDF DL 0 & - & - & - & 41.50 & 25.00 & 7.46 & 16.40 & 3.00 & 13.2 & 4.33 & 3.11 & 8.56 & -0.83 & $1.8 \mathrm{E}-06$ \\
\hline
\end{tabular}

\section{Results}

Electron energy distribution functions are presented over a range of spatial locations in the discharge chamber of the LM4 thruster. The EEDF's are displayed as a function of bias voltage with respect to discharge cathode common. As a result, the right side of the figures, with potentials near the local plasma potential, corresponds to "cool" electrons. The crossing of the horizontal axis, on right side of the EEDF plots, corresponds to the local plasma potential and therefore shifts as a function of spatial locations. The plasma potential data are determined at each spatial location from floating emissive probe results for equivalent thruster operation. ${ }^{26}$ The plasma potential mappings indicate a low-potential cathode plume and a high-potential bulk discharge plasma with a double layer potential gradient structure transitioning between the two regions. The left hand side of the EEDF's corresponds to the "hot" electrons. The reader should keep in mind that the horizontal axis of the EEDF from right to left corresponds to increasing electron kinetic energy. A schematic legend to read the EEDF's is illustrated in Figure 9.

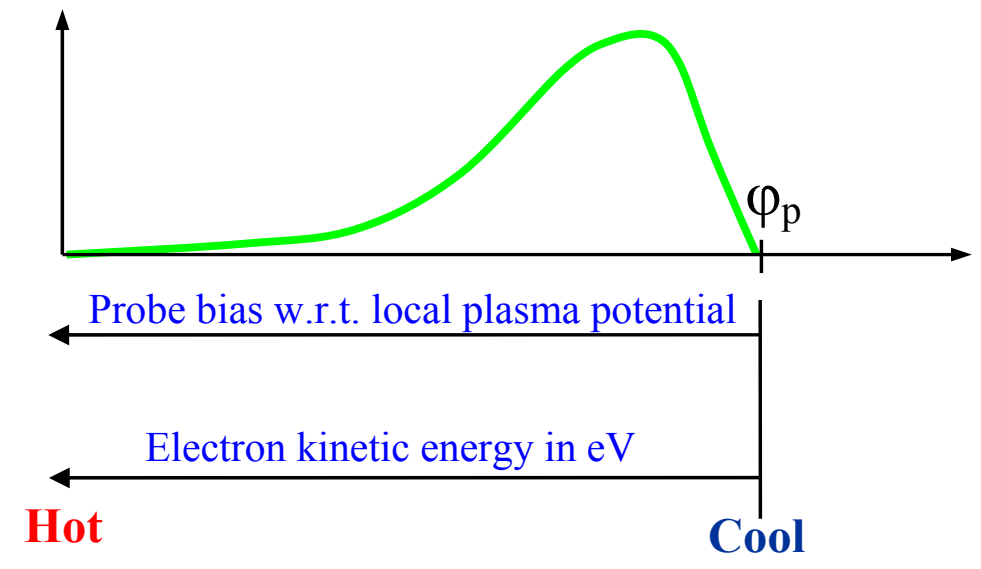

Figure 9. Electron energy distribution function (EEDF) schematic relating the EEDF bias voltage to electron kinetic energy. 


\section{A. Druyvesteyn (Second Derivative) Method EEDF's}

The application of the Druyvesteyn method provides a technique to measure EEDF's near the DCA with beam extraction. The resultant EEDF's from the Druyvesteyn method are illustrated in Figures 10, 11, and 13. The EEDF's are plotted as a function of position and are grouped by either constant radial location (indicating the EEDF evolution as progressing downstream in the axial direction) or for constant axial location (indicating the EEDF evolution with increasing distance from DCA centerline). The latter serves as a more interesting representation since the plasma potential gradients are larger in the radial direction and will illustrate the EEDF evolution across the double layer potential gradient. The data are similar for all operating conditions with beam extraction and therefore only one condition is illustrated in Figure 11. Similarly, the EEDF's without beam extraction are similar and are represented by Figure 10. The EEDF data illustrated in Figure 11 are also shown in Figure 14 displayed in grouping of constant radial location.

\section{Beam Extraction}

The EEDF's measured with beam extraction are illustrated in Figure 11. Near the DCA, inside the cathode plume, the EEDF's are single-hump distributions at peak energies of $3-10$ volts with respect to the local plasma potential in this region. Along centerline, in the cathode plume, axial acceleration of electrons is evident as the distributions become more broad with peak voltages at higher energy. The EEDF's transition from a single-hump to a plateau or double-hump distribution radially through the spatial region of the double layer potential gradient. This results from the acceleration of electrons across the double layer gradient. Outside the double layer, in the main discharge plasma, the two-hump and plateau EEDF's quickly become thermalized. The resultant main discharge plasma EEDF is a single-hump with a noticeable high-energy tail. The trends observed in the EEDF measurement are supported by the plasma potential mappings in the LM4 thruster in which a gradual axial potential gradient and abrupt radial gradient are observed. ${ }^{26}$

For the near-optics probe, most of the EEDF's are characterized by a single-hump with a gradual drop off towards higher energies. This may be due to the evolution of the EEDF from a single-hump distribution in which the higher-energy electrons in the main discharge are able to overcome the double layer gradient. As they proceed through the double layer, they lose some of their energy contributing to the large hump near the local plasma potential. In some cases, a double-hump distribution is noticeable illustrating this effect.

\section{Discharge-Only Operation}

The EEDF's measured without beam extraction are illustrated in Figure 10. Inside the discharge cathode plume, the EEDF's are single-hump distributions with peak energies of $5-8 \mathrm{eV}$ with respect to the local plasma potential. As the EEDF's evolve with the transition through the double layer gradient (also observed in plasma potential mappings without a beam) the single-hump distributions shift with the corresponding increase in local plasma potential and broaden. Near the DCA across the double layer, there are no double-hump distributions observed. Outside the double layer, in the bulk discharge plasma, a single-hump distribution with a high-energy tail is observed.

\section{Beam Effects}

Comparison of Figures 10 and 11 illustrate the effect of beam extraction on the EEDF's and therefore will bring to light the changes in electron temperature observed with/without beam extraction in previous Langmuir probe testing in the LM4 thruster. ${ }^{25}$ When a beam is extracted, the high-energy tail of the EEDF's across and outside of the double layer are more broad. This may result from the higher discharge voltage oscillations with a beam driving a fluctuating double layer leading to a more broad range of electron energies. The electrons gain a more distributed range of energies when passing through the double layer (acceleration and deceleration for the corresponding electron species) if it is fluctuating leading to an effective increase in the measured electron temperature. It is not understood why the near-DCA double-hump distribution is not observed in discharge-only operation since potential structures exist to accelerate electrons across the double layer. Near the ion optics, similar EEDF's are measured for discharge-only operation compared to beam extraction EEDF's. 


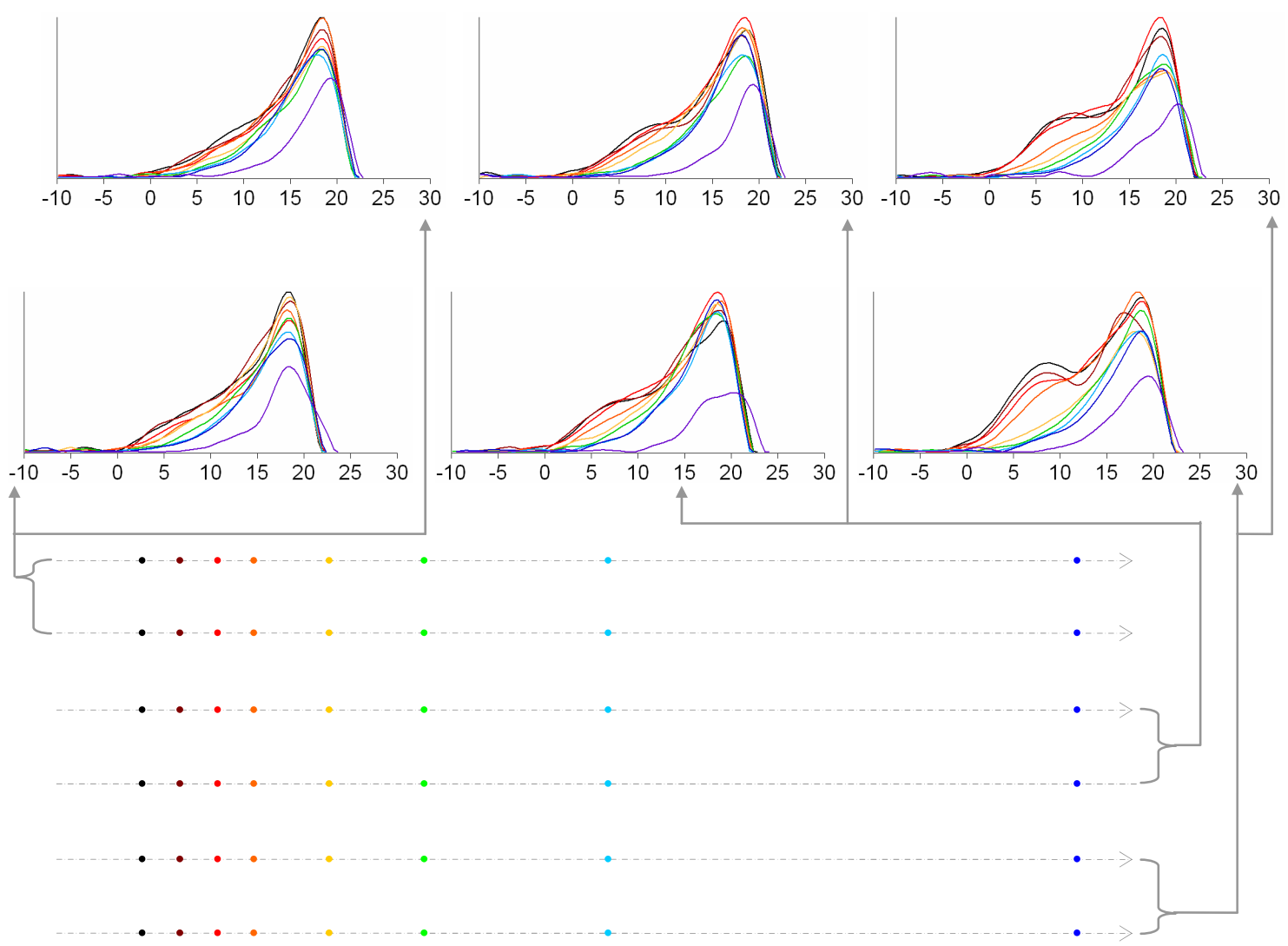

Near-optics region (above), $\bullet$ is approximately $25 \mathrm{~mm}$ from anode wall

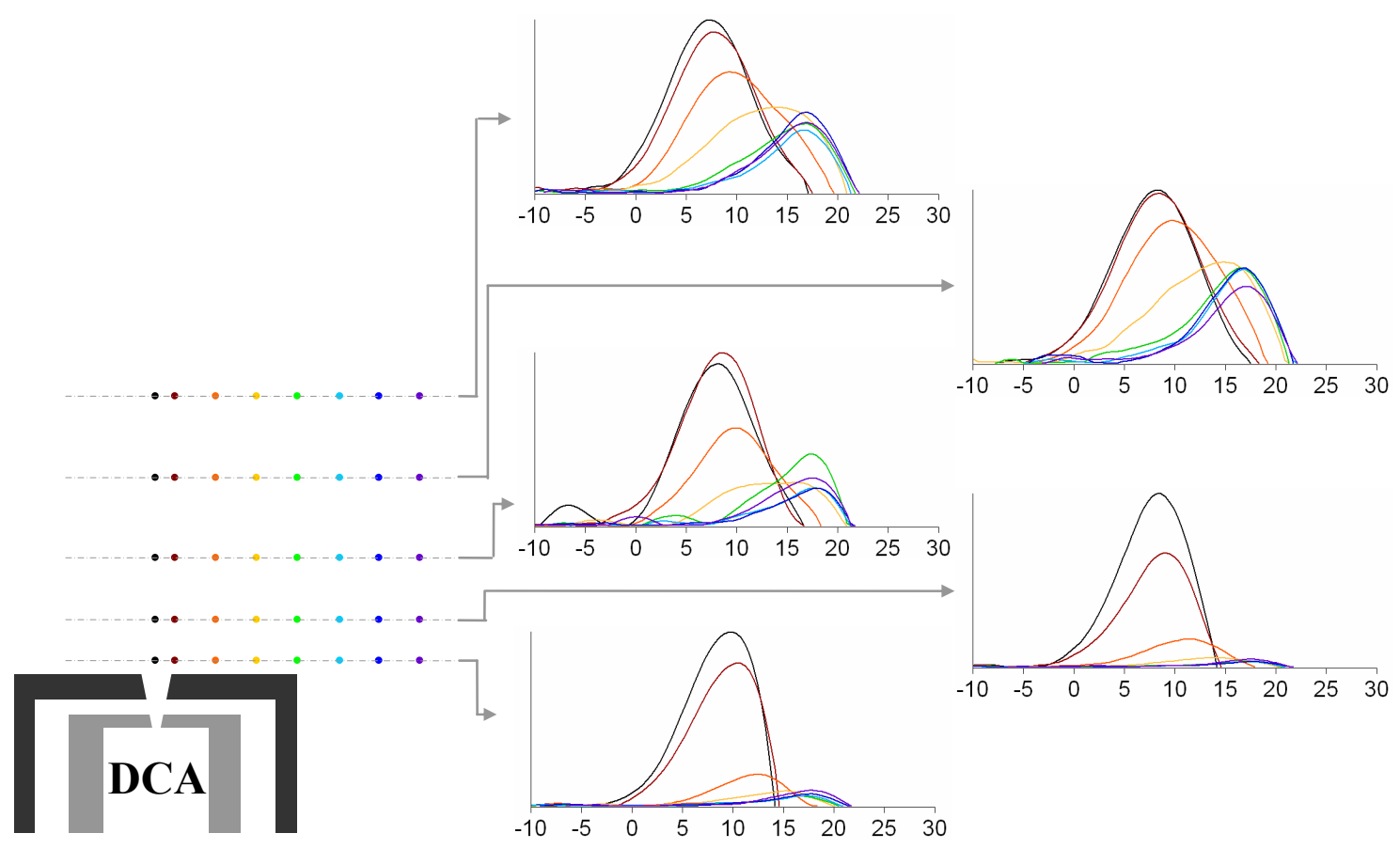

Figure 10. EEDF's for various spatial locations as a function of probe bias voltage with respect to cathode common at DEEDF DL 8. 


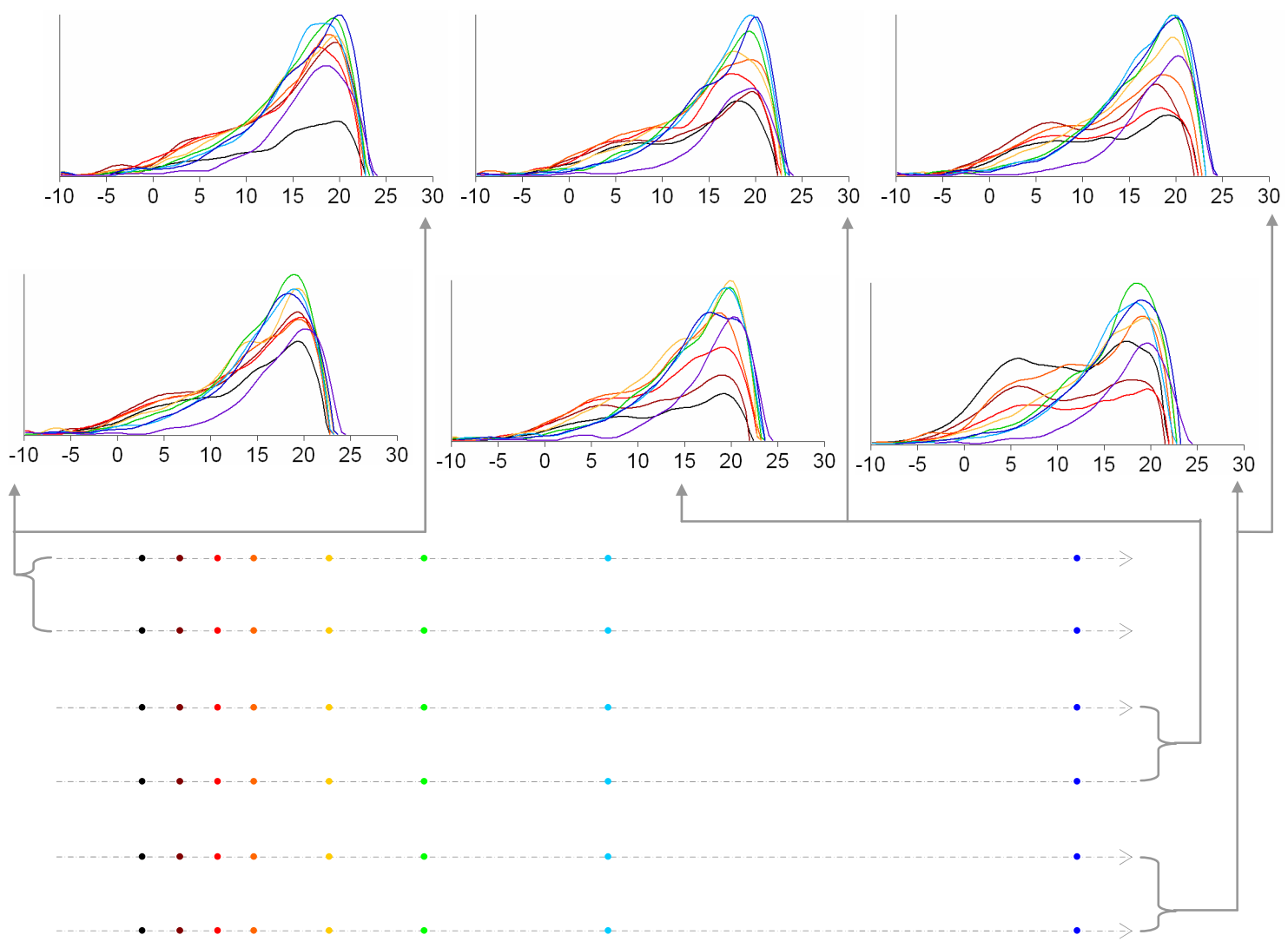

Near-optics region (above), • is approximately $25 \mathrm{~mm}$ from anode wall

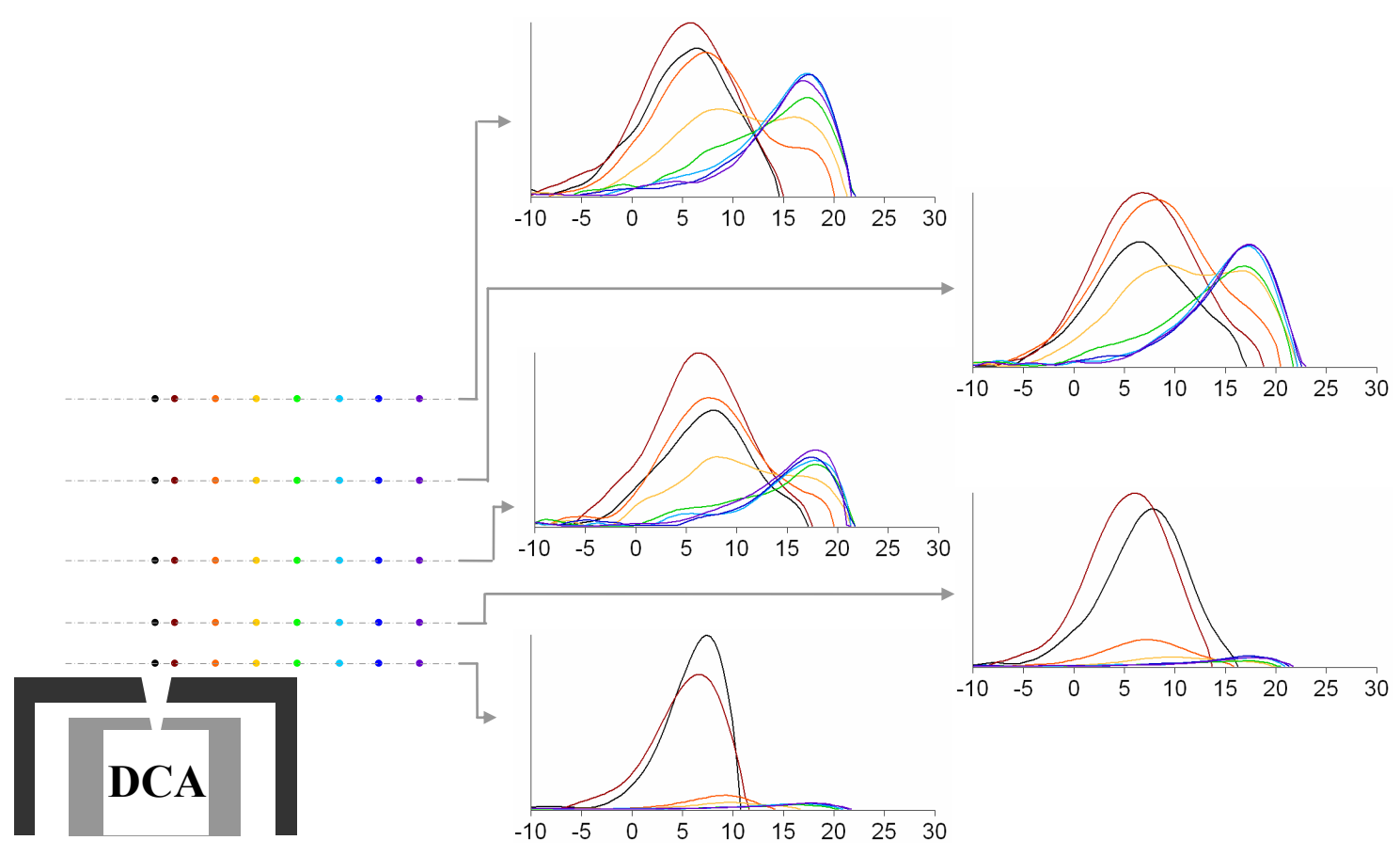

Figure 11. EEDF's for various spatial locations as a function of probe bias voltage with respect to cathode common at DEEDF TOC 34'. 


\section{B. Harmonic Method EEDF's}

Electron energy distribution functions (EEDF's) are measured near the DCA for a variety of operating conditions. The harmonic method does not rely on a numeric derivative, which can introduce error when differentiating. One of the drawbacks of the harmonic setup is that in order to get a measurable signal, the amplitude of the high-frequency sin wave was increased to 4 volts pk-pk. This will tend to smooth out the measured distribution, removing features that are smaller, in width, than 2 volts.

Another drawback is that the harmonic method is applied to thruster operation without a beam. The large number of electronics prevented floating all the equipment in a safe manner. In comparing the results from the Druyvesteyn method, illustrated in Figure 10 and Figure 11, the extraction of a beam has definite shape and broadening effects on the measured EEDF's. In spite of this change, the harmonic EEDF's are useful to verify the Druyvesteyn method EEDF's (and smoothing routine) as it is possible to compare the EEDF's without beam extraction near-DCA from the Druyvesteyn method to those obtained form the harmonic method.

The harmonic method EEDF's are similar for all discharge-only operating conditions investigated and therefore one mapping is illustrated in Figure 12. There is a single-hump distribution inside the discharge cathode plume. Moving in the radial direction, the single-hump shifts with the increase of local plasma potential, but becomes more broad, still extending to high-energy. The broadening creates a high-energy tail.

For equivalent spatial locations inside the discharge chamber, the Druyvesteyn method EEDF's are comparable to those measured by the harmonic method verifying both techniques, Figures 12 and 13. Again, the EEDF's inside the cathode plume are single hump distribution with a peak energy approximately $5-8$ volts with respect to local plasma potential.

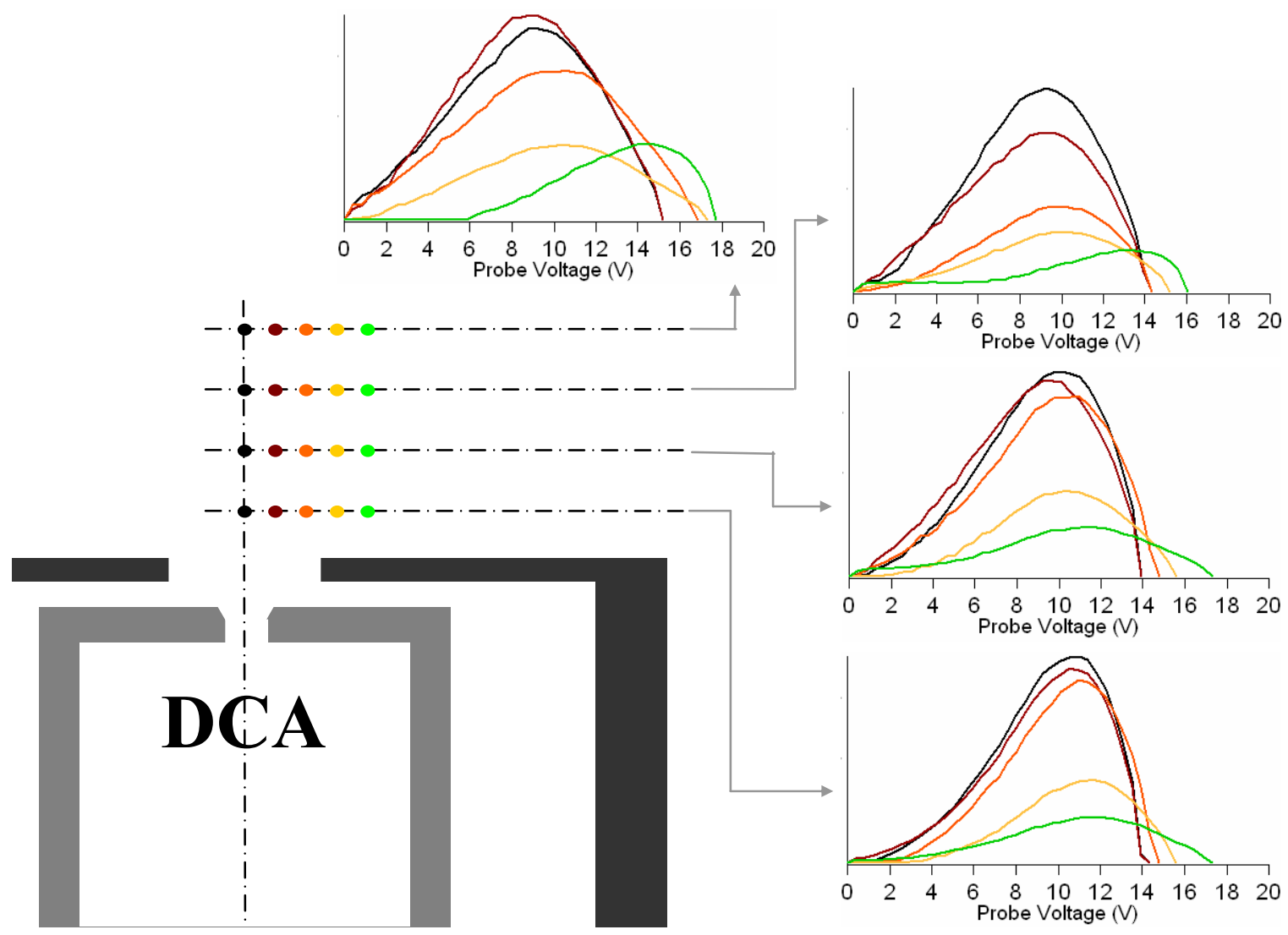

Figure 12. LM4 HEEDF DL 34' illustrating the electron energy distributions as a function of bias voltage. Each plot represents various radial spatial locations at the same axial distance from the DCA. 


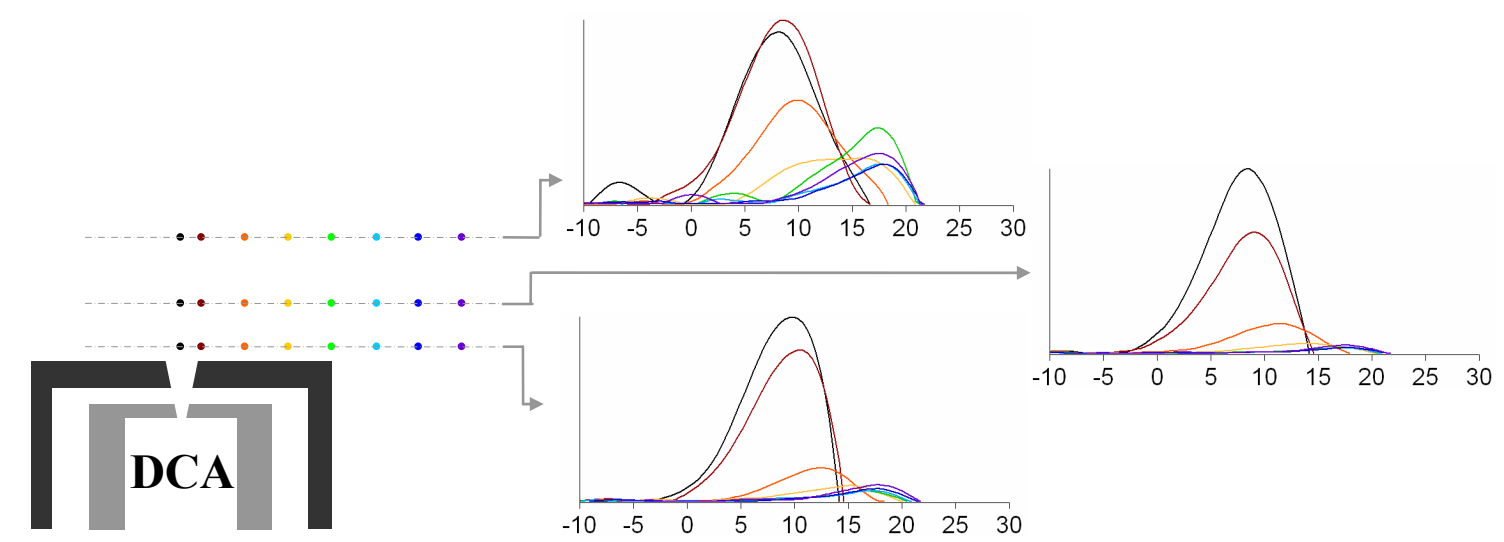

Figure 13. EEDF's for various spatial locations as a function of probe bias voltage with respect to cathode common at DEEDF DL 8.

\section{Discussion}

In parallel investigations, it is found that the plasma parameter mappings closely follow the magnetic field streamlines. The high-density cathode plume is established by an axial magnetic field near the DCA. ${ }^{25,26,30}$ As illustrated in plasma potential measurements, the magnetic field that confines the electrons to a narrow plume establishes a free-standing double layer potential gradient. ${ }^{26}$ The double layer gradient enhances radial electron motion across the largely axial magnetic field by electrostatically accelerating electrons from the DCA plume towards the bulk discharge plasma. The electron temperature contours illustrate a discharge cathode plume where low electron temperatures exist $(2-4 \mathrm{eV}){ }^{25}$ Outside of this plume, the electron temperature gradually increases by a few volts to the bulk discharge electron temperatures of 4 to $7 \mathrm{eV} .{ }^{25}$ The electron temperature assumes a Maxwellian distribution. The potential gradient structure, i.e. double layer, accelerates electrons from the discharge plume to the bulk plasma resulting in an increase in the electron temperature. This is supported by analysis of the electron energy distribution functions inside the LM4 discharge in the various discharge chamber regions: in the discharge cathode plume, across the double layer, and in the bulk discharge plasma. The elevated electron temperature through the double layer is reduced in the bulk discharge as the higher energy electrons become thermalized, though a highenergy tail remains.

The rise in electron temperature is tied to the potential gradients across the boundary between the cathode plume and bulk discharge plasma that accelerates electrons across the boundary thereby increasing their energy. The double layer potential profile also decelerates the high-energy electrons that overcome the potential gradient when moving from the appropriate discharge voltage bulk plasma to the low-potential cathode plume. This effectively replenishes the low-energy electrons in the discharge cathode plume confirmed in the analysis of the electron energy distribution functions. Axial acceleration of electrons is also observed, but to a lesser extend. This agrees well with the measured LM4 plasma potential data that indicates a gradual axial potential gradient and an abrupt radial potential gradient from the cathode plume to bulk discharge plasma.

The extraction of a beam results in a slight increase, of one or two $\mathrm{eV}$ when compared to data taken without beam extraction. This may be partially due to the increase in discharge voltage associated with beam extraction. The increase in the electron temperatures with beam extraction indicate the coupled nature of the beam and discharge cathodes implying that beam extraction is needed to accurately represent flight-like thruster operating conditions. Beam extraction tends to broaden the measured EEDF's towards higher energies.

Throughout the LM4 investigation, the effects of beam extraction are determined by turning off the high-voltage power supplies. The equivalent mass flow rates and discharge currents maintain equivalent number density profiles with and without a beam. The reduction in discharge voltage without a beam decreases the measured plasma potentials inside the discharge chamber. The electron temperatures with beam extraction are slightly higher in magnitude than the discharge-only values. Examination of the electron energy distribution functions (EEDF's) highlights more broad distributions as the reason for this electron temperature increase likely due to discharge voltage oscillations. From the LM4 equivalent mass flow approach and the $30-\mathrm{cm}$ NSTAR equivalent discharge voltage approach, it is evident that the thruster must be operated at with beam extraction to encompass equivalent electron temperatures, number densities, and plasma potentials to flight conditions. ${ }^{23-26,30}$ All of the discharge plasma parameters are important in describing the discharge plasma environment and therefore the DCA erosion 
mechanisms. The shorting of the discharge cathode keeper to cathode common does not have an effect on the measured EEDF's in the discharge plasma outside of the keeper sheath.

\section{Conclusions}

Two methods of mapping the electron energy distribution functions inside the discharge chamber of a $40-\mathrm{cm}$ NEXT engine are demonstrated. The two methods illustrate EEDF's that are insensitive to thruster power level. The methods produce comparable results. Small differences can be attributed to operation with a beam for the Druyvesteyn method and without a beam for the harmonic method. The extraction of a beam broadens the EEDF's observed in the double layer transition region due to the increase in discharge voltage oscillations.

The harmonic method is used very close to the DCA, while the Druyvesteyn method (second derivative method) is employed over a much larger spatial domain. Both methods indicate electron energy distributions that are singlehump inside the discharge cathode plume. Across the double layer potential gradient with beam extraction, the EEDF's become stretched or plateau-like and for some cases a second-hump appears due to the accelerated electron population. The two-hump and plateau-like distributions result from radial acceleration of electrons across the freestanding double layer potential gradient that forms the transition from the low-potential cathode plume and the discharge voltage potential bulk discharge plasma. The two-hump distribution and stretched distributions are quickly thermalized outside of the double layer in the bulk discharge. The resultant bulk discharge distributions become a single-hump, but with a high-energy tail.

Without beam extraction, the EEDF's do not illustrate double-hump distributions in the double layer, but remain single-hump distributions. This indicated the coupled nature of the discharge plasma with the beam and the need for beam extraction to simulate actual flight conditions. Axial acceleration of electrons from the cathode plume to the bulk discharge plasma is observed, but to a lesser extent. This agrees with the smaller and more gradual axial potential gradient in the LM4 thruster compared to the radial potential gradient across the double layer. The electron temperature profiles in the discharge cathode plume are $2-4 \mathrm{eV}$ and increase off-axis to $4-7 \mathrm{eV}$. This increase is caused by the acceleration of electrons across the double layer and is confirmed by the electron energy distribution measurements. Outside the off-axis maximum, the electron temperature decreases as the accelerated ions are thermalized. 

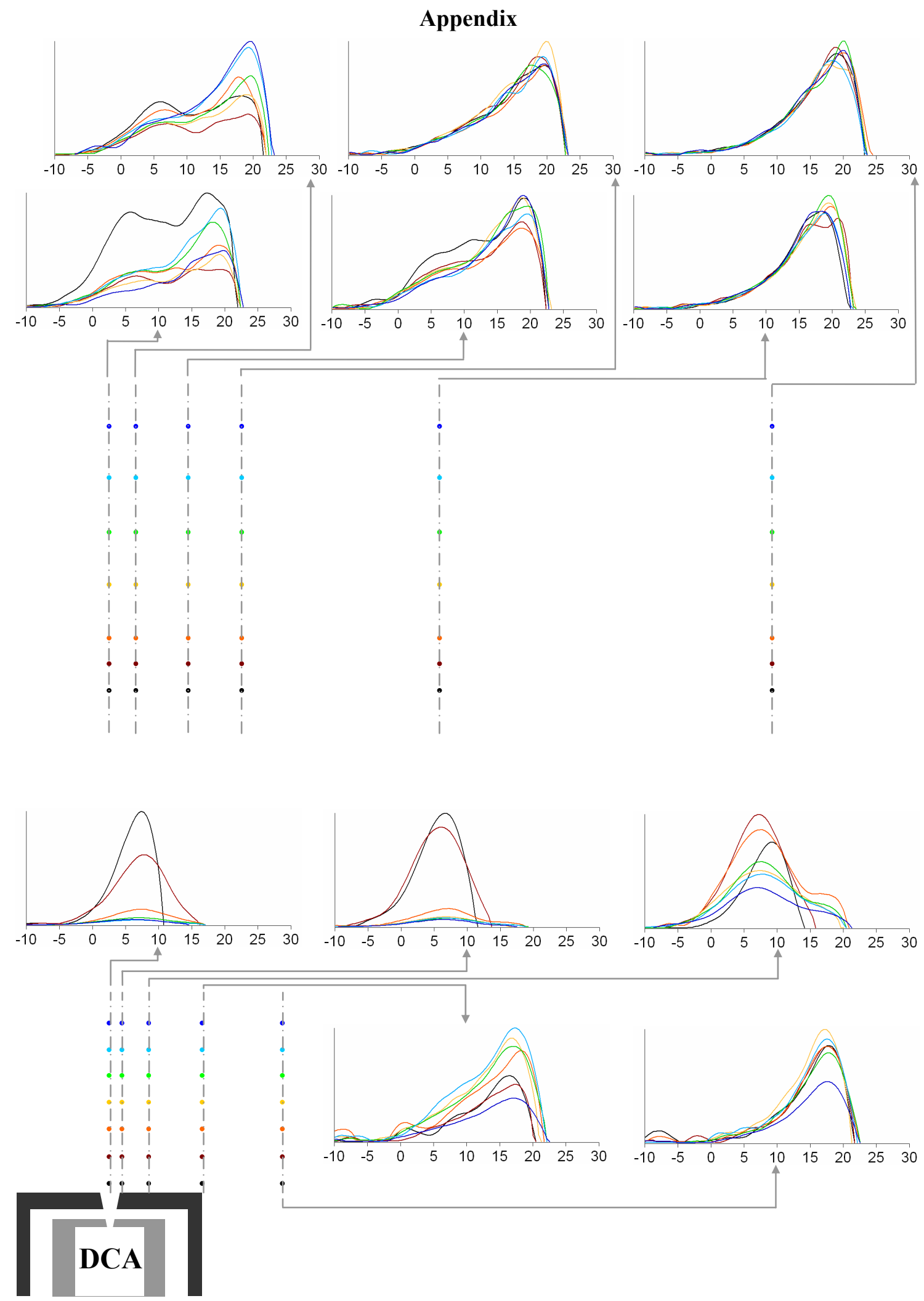

Figure 14. EEDF's for various spatial locations as a function of probe bias voltage with respect to cathode common at DEEDF TOC 34'. 


\section{Acknowledgments}

We would like to thank Mr. Michael Patterson of the NASA Glenn Research Center (GRC) for the financial support of this research through research grant NAG3-2216 and for use of government equipment. We would like to acknowledge Dr. John Foster (grant monitor) and Dr. George Williams who have been principal contacts at NASA GRC. We would also like to thank the technicians at NASA GRC, Terry Larrow at the University of Michigan, and Bob Roman who assisted in building the LM4 thruster.

\section{References}

${ }^{1}$ Choueiri, E. Y., "A Critical History of Electric Propulsion: The First 50 Years (1906 - 1956)," Journal of Propulsion and Power, Vol. 20, No. 2, pp. 193-203, March-April 2004.

${ }^{2}$ Polk, J. E., Kakuda, R. Y., Anderson, J. R., Brophy, J. R., Rawlin, V. K., Patterson, M. J., Sovey, J. S. and Hamley, J., "Performance of the NSTAR Ion Propulsion System on the Deep Space One Mission," AIAA-2001-0965, 39th AIAA Aerospace Sciences Meeting and Exhibit Joint Propulsion Conference, Reno, NV, January 8-11, 2001.

${ }^{3}$ Sengupta, A., Brophy, J. R. and Goodfellow, K. D., "Status of the Extended Life Test of the Deep Space 1 Flight Spare Ion Engine after 30,352 Hours of Operation," AIAA-2003-4558, 39th AIAA / ASME / SAE / ASEE Joint Propulsion Conference, Huntsville, AL, July 20-23, 2003.

${ }^{4}$ Patterson, M. J., Rawlin, V. K., Sovey, J. S., Kussmaul, M. and Parkes, J., "2.3 kW Ion Thruster Wear Test," AIAA-19952516, 31st AIAA / ASME / SAE / ASEE Joint Propulsion Conference, San Diego, CA, July 10-12.

${ }^{5}$ Polk, J. E., Patterson, M. J., Brophy, J. R., Rawlin, V. K., Sovey, J. S., Myers, R. M., Blandino, J. J., Goodfellow, K. D. and Garner, C. E., "A 1000 Hour Wear Test of the NASA NSTAR Ion Thruster," AIAA-1996-2784, 32nd AIAA / ASME / SAE / ASEE Joint Propulsion Conference, Lake Buena Vista, FL, July 1-3.

${ }^{6}$ Polk, J. E., Anderson, J. R., Brophy, J. R., Rawlin, V. K., Patterson, M. J., Sovey, J. S. and Hamley, J., "An overview of the results from an 8200 hour wear test of the NSTAR ion thruster," AIAA-1999-2446, 35th AIAA / ASME / SAE / ASEE Joint Propulsion Conference, Los Angeles, California, June 20-24, 1999.

${ }^{7}$ Polk, J. E., Anderson, J. R., Brophy, J. R., Rawlin, V. K., Patterson, M. J. and Sovey, J. S., "The Effect of Engine Wear on Performance in the NSTAR 8000 Hour Ion Engine Endurance Test," AIAA-1997-0869, 33rd AIAA / ASME / SAE / ASEE Joint Propulsion Conference, Seattle, WA, July 6-9.

${ }^{8}$ Oleson, S.Katz, I., "Electric Propulsion for Project Prometheus," AIAA-2003-5279, 39th AIAA / ASME / SAE / ASEE Joint Propulsion Conference, Huntsville, AL, July 20-23, 2003.

${ }^{9}$ Oleson, S. R., "Electric Propulsion Technology Development for the Jupiter Icy Moons Orbiter Project," AIAA-2004-3449, 40th AIAA / ASME / SAE / ASEE Joint Propulsion Conference, Fort Lauderdale, Florida, July 11-14, 2004.

${ }^{10}$ Cupples, M., Coverstone, V. and Woo, B., "Application of Solar Electric Propulsion to a Comet Surface Sample Return Mission," AIAA-2004-3804, 40th AIAA / ASME / SAE / ASEE Joint Propulsion Conference, Fort Lauderdale, FL, July 11-14.

${ }^{11}$ Oh, D., Benson, S., Witzberger, K. and Cupples, M., "Deep Space Mission Applications for NEXT: NASA's Evolutionary Xenon Thruster," AIAA-2004-3806, 40th AIAA / ASME / SAE / ASEE Joint Propulsion Conference, Fort Lauderdale, FL, July 11-14.

${ }^{12}$ Benson, S.Patterson, M. J., "Development status of NEXT: NASA's evolutionary xenon thruster," IEPC-03-0288, 28th International Electric Propulsion Conference, Toulouse, France, March 17-21, 2003.

${ }^{13}$ Williams, G. J., Smith, T. B. and Gallimore, A. D., "30 cm Ion Thruster Discharge Cathode Erosion," IEPC-01-306, 27th International Electric Propulsion Conference, Pasadena, CA, October 15-19, 2001.

${ }^{14}$ Williams, G. J., Smith, T. B., Patrick, T. A. and Gallimore, A. D., "Characterization of the FMT-2 discharge cathode plume," IEPC-99-104, 26th International Electric Propulsion Conference, Kitakyushu, Japan, October 1999.

${ }^{15}$ Farnell, C. C., Williams, J. D. and Wilbur, P. J., "Characteristics of energetic ions emitted from hollow cathodes," IEPC-03072, 28th International Electric Propulsion Conference, Toulouse, France, March 17-21, 2003.

${ }^{16}$ Foster, J. E.Patterson, M. J., "Plasma emission characteristics from a high current hollow cathode in an ion thruster discharge chamber," AIAA-2002-4102, 38th AIAA / ASME / SAE / ASEE Joint Propulsion Conference, Indianapolis, IN, July 7$10,2002$.

${ }^{17}$ Foster, J. E.Patterson, M. J., "Characterization of Downstream Ion Energy Distributions from a High Current Hollow Cathode in a Ring Cusp Discharge Chamber," AIAA-2003-4865, 39th AIAA / ASME / SAE / ASEE Joint Propulsion Conference, Huntsville, AL, July 20-23, 2003.

${ }^{18}$ Foster, J. E., Soulas, G. C. and Patterson, M. J., "Plume and Discharge Plasma Measurements of an NSTAR-type Ion thruster," AIAA-2000-3812, 36th AIAA / ASME / SAE / ASEE Joint Propulsion Conference, Huntsville, AL., July 16-19, 2000.

${ }^{19}$ Sengupta, A., Goebel, D. M., Fitzgerald, D., Owens, A., Tynan, G. and Doerner, R., "Experimentally Determined Neutral Density and Plasma Parameters in a $30 \mathrm{~cm}$ Ion Engine," AIAA-2004-3613, 40th AIAA / ASME / SAE / ASEE Joint Propulsion Conference, Fort Lauderdale, FL, July 11-14, 2004.

${ }^{20}$ Goebel, D. M., Jameson, K. K., Watkins, R. M. and Katz, I., "Hollow Cathode and Keeper-Region Plasma Measurements using Ultra-Fast Miniature Scanning Probes," AIAA-2004-3430, 40th AIAA / ASME / SAE / ASEE Joint Propulsion Conference, Fort Lauderdale, FL, July 11-14, 2004. 
${ }^{21}$ Herman, D. A.Gallimore, A. D., "A high-speed axial reciprocating probe positioning system for interrogating the discharge plasma of a $30 \mathrm{~cm}$ ion thruster," AIAA-2002-4256, 38th AIAA / ASME / SAE / ASEE Joint Propulsion Conference, Indianapolis, IN, July 7-10, 2002.

${ }^{22}$ Herman, D. A.Gallimore, A. D., "Comparison of Discharge Plasma Parameters in a 30-cm NSTAR Type Ion Engine with and without Beam Extraction," AIAA-2003-5162, 39th AIAA / ASME / SAE / ASEE Joint Propulsion Conference, Huntsville, Alabama, July 20-23, 2003.

${ }^{23}$ Herman, D. A.Gallimore, A. D., "Near Discharge Cathode Assembly Plasma Potential Measurements in a $30 \mathrm{~cm}$ NSTARtype Ion Engine amidst Beam Extraction," AIAA-2004-3958, 40th AIAA / ASME / SAE / ASEE Joint Propulsion Conference, Fort Lauderdale, FL, July 11-14.

${ }^{24}$ Herman, D. A., McFarlane, D. S. and Gallimore, A. D., "Discharge plasma parameters of a $30 \mathrm{~cm}$ ion thruster measured without beam extraction using a high-speed axial reciprocating probe positioning system," IEPC-03-0069, 28th International Electric Propulsion Conference, Toulouse, France, March 17-21, 2003.

${ }^{25}$ Herman, D. A.Gallimore, A. D., "Discharge Chamber Plasma Structure of a 40-cm NEXT-type Ion Engine," AIAA-20054250, 41st AIAA / ASME / SAE / ASEE Joint Propulsion Conference, Tucson, AZ, July 10-13, 2005.

${ }^{26}$ Herman, D. A.Gallimore, A. D., "Discharge Chamber Plasma Potential Mapping of a 40-cm NEXT-type Ion Engine," AIAA-2005-4251, 41st AIAA / ASME / SAE / ASEE Joint Propulsion Conference, Tucson, AZ, July 10-13, 2005.

${ }^{27}$ Soulas, G. C., Domonkos, M. T. and Patterson, M. J., "Performance Evaluation of the NEXT Ion Engine," AIAA-20035278, 39th AIAA / ASME / SAE / ASEE Joint Propulsion Conference, Huntsville, AL, July 20-23, 2003.

${ }^{28}$ Soulas, G. C., Kamhawi, H., Patterson, M. J., Britton, M. A. and Frandina, M. M., "NEXT Ion Engine 2000 Hour Wear Test Results," AIAA-2004-3791, 40th AIAA / ASME / SAE / ASEE Joint Propulsion Conference, Fort Lauderdale, FL, July 1114.

${ }^{29}$ Hoskins, W. A., Wilson, F. C., Polaha, J., Talerico, L., Patterson, M. J., Soulas, G. C. and Sovey, J. S., "Development of a Prototype Model Ion Thruster for the NEXT System," AIAA-2004-4111, 40th AIAA / ASME / SAE / ASEE Joint Propulsion Conference, Fort Lauderdale, FL, July 11-14.

${ }^{30}$ Herman, D. A., "The Use of Electrostatic Probes to Characterize the Discharge Plasma Structure and Identify Discharge Cathode Erosion Mechanisms in Ring-Cusp Ion Thrusters," Thesis, Dept. of Aerospace Engineering, University of Michigan, Ann Arbor, MI, 2005.

${ }^{31}$ Haas, J. M., "Low-Perturbation Interrogation of the Internal and Near-field Plasma Structure of a Hall thruster using a High-Speed Probe Positioning System," Ph. D. Thesis, Dept. of Aerospace Engineering, University of Michigan, Ann Arbor, MI, 2001.

${ }^{32}$ Haas, J. M., Gallimore, A. D., McFall, K. and Spanjers, G. G., "Development of a high-speed, reciprocating electrostatic probe system for Hall thruster interrogation," Review of Scientific Instruments, Vol. 71, No. 11, pp. 4131, November 2000.

${ }^{33}$ Haas, J. M.Gallimore, A. D., "Characterization of the internal plasma structure of a 5kw hall thruster," IEPC-99-078, 26th International Electric Propulsion Conference, Kitakyushu, Japan, October 1999.

${ }^{34}$ Hofer, R. R.Gallimore, A. D., "Recent Results from Internal and Very-Near-Field Plasma Diagnostics of a High Specific Impulse Hall thruster," IEPC-03-037, 28th International Electric Propulsion Conference, Toulouse, France, March 17-21, 2003.

${ }^{35}$ Williams, G. J., Smith, T. B., Gulczinski, F. S., Beal, B. E., Gallimore, A. D. and Drake, R. P., "Laser Induced Fluorescence Measurement of Ion Velocities in the Plume of a Hall Effect Thruster," AIAA-1999-2424, 35th AIAA / ASME / SAE / ASEE Joint Propulsion Conference, Los Angeles, CA, June 20-23, 1999.

${ }^{36}$ Williams, G. J., Domonkos, M. T. and Chavez, J. M., "Measurement of doubly charged ions in ion thruster plumes," IEPC01-310, 27th International Electric Propulsion Conference, Pasadena, CA, October 15-19, 2001

${ }^{37}$ Mott-Smith, H. M.Langmuir, I., "The Theory of Collectors in Gaseous Discharges," Physical Review, Vol. 28, pp. 727-763, October, 1926.

${ }^{38}$ Langmuir, I., "The Interaction of Electron and Positive Ion Space Charges in Cathode Sheaths," Physical Review, Vol. 33, pp. 954-989, June 1929.

${ }^{39}$ Walker, M. L. R.Gallimore, A. D., "Hot Flow Pressure Map of a Vacuum Facility as a function of Flow Rate to study Facility Effects," JPC04, Toulouse, France, March 17-21, 2003.

${ }^{40}$ Walker, M. L. R., Gallimore, A. D., Chunpei, C. and Boyd, I. D., "Pressure Map of a Facility as a function of Flow Rate to study Facility Effects," AIAA-2002-3815, 38th Joint Propulsion Conference, Indianapolis, IN, July 7-10, 2002.

${ }^{41}$ Passoth, E., Kudrna, P., Csambal, C., Behnke, J. F., Tichy, M. and Helbig, V., "An experimental study of plasma density determination by a cylindrical Langmuir probe at different pressures and magnetic fields in a cylindrical magnetron discharge in heavy rare gases," Journal of Physics D: Applied Physics, Vol. 30, pp. 1763, June 1997.

${ }^{42}$ Aikawa, H., "The Measurement of the Anisotropy of Electron Distribution Function of a Magnetized Plasma," Journal of the Physical Society of Japan, Vol. 40, No. 6, pp. 1741, June 1976. 